\title{
Chondroitin Sulfate Flourishes Gut Sulfatase-Secreting Bacteria To Damage Mucus Layers, Leak Bacterial Debris, And Trigger Inflammatory Lesions In Mice
}

\author{
Tao Liao ${ }^{1 *}$, Yan-Ping Chen ${ }^{1 *}$, Li-Li Tan ${ }^{1}$, Chang-Qing Li ${ }^{1}$, Qi Wang², Shui-Qing \\ Huang $^{3}$, Xin-An Huang ${ }^{1}$, Qin $X u^{1 * *}$, Qing-Ping Zeng ${ }^{1 * *}$ \\ * Equal contributors to this work \\ **Correspondence: qpzeng@gzucm.edu.cn; xuqin@gzucm.edu.cn
}

\begin{abstract}
Author details
${ }^{1}$ Tropical Medicine Institute, Guangzhou University of Chinese Medicine, Guangzhou 510405, China.

${ }^{2}$ Clinical Pharmacology Institute, Guangzhou University of Chinese Medicine, Guangzhou 510405 China.

${ }^{3}$ Basic Medical Science College, Guangzhou University of Chinese Medicine, Guangzhou 510405 China.
\end{abstract}

\begin{abstract}
Background: An interaction of the food types with the gut microbiota changes is deeply implicated in human health and disease. To verify whether animal-based diets would lead to gut dysbiosis, systemic inflammation and inflammatory pathogenesis, we fed mice with chondroitin sulfate (CS), a sulfate-containing O-glycan naturally occurring in livestock and poultry products, and monitored the dynamic changes of microbial flores, inflammatory signatures, and pathogenic hallmarks.
\end{abstract}

Results: A metagenomic gut microbiota analysis revealed the overgrowth of sulfatasesecreting bacteria and sulfate-reducing bacteria in the gastrointestinal tracts of mice upon daily CS feeding. Sulfatase-secreting bacteria compromise gut integrity through prompting mucin degradation and mucus lesions, which were evident from the upregulation of secretary leukocyte protease inhibitor (SLPI) and mucin 1/4 (MUC-1/4). A synchronous elevation of lipopolysaccharide (LPS) and tumor necrosis factor $\alpha$ (TNF- $\alpha$ ) levels in the serum as well as cerebral, hepatic, cardiac and muscular tissues suggests bacterial endotoxinemia, chronic low-grade inflammation and mitochondrial dysfunction, eventually leading to the onset of global inflammatory pathogenesis towards arthritis, dementia, tumor, and fatty liver.

Conclusions: CS triggers the early-phase and multi-systemic pathogenesis like arthritis, dementia, tumor, and fatty liver by enhancing gut opportunistic infection and evoking low-grade inflammation in mice. A plausible reason for the inconsistency of CS in treatment of osteoarthritis (OA) was also discussed.

Keywords: Chondroitin sulfate, lipopolysaccharide, sulfatase-secreting bacteria, sulfate-reducing bacteria, gut microbiota, opportunistic infection

\section{Background}

Human and animal gastrointestinal tracts are colonized by commensal microbes, mainly including bacteria and fungi, with differential and food-dependent gut microbiota compositions among individuals [1]. An animal-based high fat/high protein food intake increases the abundance of 
Bacteroides, whereas a plant-based high fiber food intake increases the richness of Prevotella [2,3]. While a high fat/high sugar diet used in the developed "Western" nations increases the bile tolerant Bacteroides, Alistips and Bilophila, a high fiber diet eaten by the people in developing countries increases the polysaccharide degradable Firmicutes, such as Roseburia, Eubacterium, rectale and Ruminococcus bromii [4]. Children from a rural African village show a unique abundance of cellulose-degradable Prevotella and xylan hydrolyzable Xylanibacter, completely lacking in children from an urban European city [5].

Mounting evidence supports an alteration of the gut microbiota in patients with stroke [6], obesity $[7,8]$ and type 2 diabetes $[9,10]$. A recent work has validated that the altered intestinal microbiome is related to the dysfunctional motor phenotype in patients with Parkinson's disease [11]. Although an implication of a specific gut microbiota in human health and disease remains ambiguous, progresses regarding food-induced disorders have been achieved from the most recent findings. For example, metabolism of L-carnitine, a trimethylamine abundant in red meat, by the intestinal microbiota was found to accelerate atherosclerosis by conversion of L-carnitine to trimethylamine-N-oxide in mice [12]. Chondroitin sulfate (CS), a sulfate-containing ingredient in animal products including red meat, was shown to promote the overgrowth of sulfate-reducing bacteria (SRB) in aid of sulfatase-secreting bacteria (SSB), during which sulfatase degrades CS as an electric recipient for sulfate reduction [13]. The gut microbiota flourished by heme, another red meat component, was also noticed to facilitate an abnormal epithelial proliferation via reducing the S-S bond for mucolysis and opening the mucus barrier in the colon [14].

Given that an interaction of CS with SSB allows the bacterial endotoxin lipopolysaccharide (LPS) trespassing the gut barrier and entering the blood stream, it might be anticipated that CS should trigger inflammatory responses and aggravate inflammatory conditions such as inflammatory bowel disease (IBD) and osteoarthritis (OA). However, a randomized and controlled clinical trial for the treatment of cannie IBD indicated that oral CS and probiotics (resistant starch, $\beta$-glucans and mannaoligosaccharide) show improvement in selected serum biomarkers, hence assuming a reduction in disease activity [15]. Indeed, CS in combination with glucosamine or glucosamine sulfate has long been used for the dietary intervention of OA [16]. Nevertheless, it was also warned that CS should not be used to treat the symptomatic OA because of without relief [17]. Recently, it was observed that a combined therapy of CS with glucosamine sulfate or glucosamine hydrochloride exhibits no improvement of joint damage in a rabbit OA model [18], and CS plus glucosamine sulfate shows no superiority over placebo in a randomized, double-blind and placebo-controlled clinical trial in OA patients [19]. Nevertheless, a question regarding why CS is unlikely always effective on OA remains unanswered.

Considering CS impacting on the gut microbiota homeostasis described above [13], we proposed here that $\mathrm{CS}$ might exert distinctive effects on $\mathrm{OA}$ in a gut microbiota-dependent manner. In other words, CS should improve OA if gut SSB is absent, otherwise CS might aggravate OA. This is because SSB, in addition to degrade CS, can also degrade mucin-containing mucus linings, by which LPS should be leaked out from the gut. Actually, some CS-degrading bacteria, including B. thetaiotaomicron $\mathrm{J} 1$ and 82, B. ovitus $\mathrm{E} 3$ and Clostridium hathewayi $\mathrm{R} 4$, were isolated and characterized from healthy persons [20]. Additionally, it was proved that the gut microbiota is more vulnerable to CS in female mice than male mice [21]. We also assumed that the beneficial effect of CS on OA might be an essential consequence of LPS depletion by the neutralizing anti-LPS antibodies, after which a serum test would give a negative result of the inflammatory 
indicators.

It could be predicted that CS-induced opportunistic infection and enhanced mucus leakage should lead to LPS entering into the blood circulation, but anti-LPS not neutralizing all leaked LPS. Thus, an essential outcome should be that the residual LPS triggers multi-systemic inflammation and eventually causes inflammatory disorders. As supporting evidence, intranasal LPS infusion was shown to induce neuroinflammation and Parkinson's disease in rodents [22]. Our previous work also revealed that articulate LPS injections can induce synovitis, an early-phase presentation of rheumatoid arthritis [23]. In theory, LPS-elicited chronic inflammation could also lead to other inflammatory consequences, including benign tumor and even malignant cancer albeit occasionally. By identifying the gut microbiota spectra in CS-fed mice and monitoring the expression profiles of selective biomarkers involving dementia, arthritis, tumor and fatty liver, we established an association of gut dysbiosis with the multi-loci inflammatory pathogenesis. These results should shed light on elucidation of a mechanistic link of the disturbed gut microbiota to some dietary factors as a major etiological originator initiating chronic inflammation and metabolic diseases.

\section{Methods}

\section{Animals and treatment}

The female Kunming mice (nine-month old, $40-45 \mathrm{~g}$ ) that belong to an out-bred population from SWISS mice were provided by The Experimental Animal Centre of Guangzhou University of Chinese Medicine in China (Certificate No. 44005800001448). All mice were housed on a 12-h light and 12-h dark cycle at $25^{\circ} \mathrm{C}$ with ad libitum chow and free water drinking. After three-week quarantine, mice were randomly divided into a control group fed only with ad libitum chow (AL mice), a model group intragastrically administered with $250 \mu \mathrm{l} \mathrm{CS}(100 \mathrm{mg} / \mathrm{ml}$, FocusChem, Shandong, China) daily for two months in addition to Ad libitum feeding (CS mice), a model group intragastrically administered with $250 \mu \mathrm{CS}$ (FocusChem, Shandong, China) and $10^{4}$ Bacillus cereus (Huankai Microbial Sci \& Tech Co Ltd., Guangdong, China) daily for two months in addition to Ad libitum feeding (CS-BC mice), and a model group peritoneally injected with 0.25 $\mathrm{mg} / \mathrm{kg}$ LPS (Sigma Aldrich) on every two days for two weeks in addition to Ad libitum feeding (LPS mice). Three to six mice were included within each group. All experiments were approved by The Animal Care Welfare Committee of Guangzhou University of Chinese Medicine (No. SPF-2015009). The experimental protocols complies with the requirements of animal ethics issued in the Guide for the Care and Use of Laboratory Animals of the National Institute of Health (NIH), USA.

\section{Gut microbiota metagenomic analysis}

The gut microbiota in a mouse fecal sample was identified by the high-throughput 16S VX sequencing-based classification procedure. The sequencing (sample preparation, DNA extraction and detection, amplicon purification, library construction and online sequencing) and data analysis (paired end-reads assembly and quality control, operational taxonomic units cluster and species annotation, alpha diversity and beta diversity) were conducted by Novogene, Beijing, China.

\section{Polymerase chain reaction (PCR) microarray and quantitative PCR (qPCR)}

The RT² Profiler ${ }^{\text {TM }}$ PCR Array Mouse Fatty Liver ( PAMM-157Z ) was purchased from SABioscience Qiagen, Hilden, Germany. The experiment was performed by Kangchen Biotechnology Co, Ltd, Shanghai, China. RNA isolation, purity determination, electrophoresis 
monitoring, reverse transcription, and quantification were performed obeying a standard protocol.

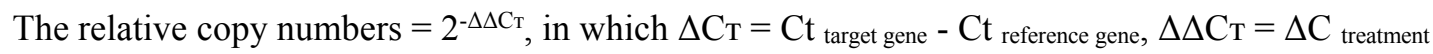
sample $-\Delta \mathrm{C}$ control sample. Each pair of primers listed in Additional file 1 were designed and applied under the following amplification condition: $95^{\circ} \mathrm{C}, 30 \mathrm{~s} ; 95^{\circ} \mathrm{C}, 3 \mathrm{~s}, 64^{\circ} \mathrm{C}, 34 \mathrm{~s}, 45$ cycles.

\section{Western blotting (WB) and enzyme-linked immunosorbent assay (ELISA)}

The reference protein glyceraldehyde-3-phosphate dehydrogenase (GAPDH), and all antigen proteins were immunoquantified by WB according to manufacture's manuals. Antibodies against mouse mucin 1 (MUC1)/MUC4, cyclin D1 (CD1), and p21 were purchased from CapitalBio Corp, China. ELISA kits for mouse tumor necrosis factor $\alpha$ (TNF- $\alpha$ ), TNF- $\alpha$ receptor 1 (TNFR1), toll-like receptor 4 (TRL4), chemokine (C-C motif) ligand 2 (CCL2), amyloid $\beta$ peptide (A $\beta$ ) and tyrosine hydroxylase (TH) were from Beijing Chenglin Biotech Co., China. ELISA kits for mouse TNF- $\alpha$, LPS, presenilin 1 (PS-1), rheumatoid factor (RF) was from Shanghai Jinma Experiment Equip Co., Ltd., China.

\section{Histochemical analysis by haematoxylin-eosin (HE) staining}

Fix the dissected tissue by immersion in a 10\% formalin solution for 4 to 8 hours at room temperature. Mount in OCT embedding compound, and freeze at -20 to $-80^{\circ} \mathrm{C}$. Cut $5-15 \mu \mathrm{m}$ thick tissue sections using a cryostat. Thaw-mount the sections onto gelatin-coated histological slides.

Slides are pre-coated with gelatin to enhance adhesion of the tissue. Dry the slides for $30 \mathrm{~min}$ on a slide warmer at $37^{\circ} \mathrm{C}$. Sections were deparaffinized by xylene, re-hydrated by gradient alcohol, and washed in distilled water. After haematoxylin staining, wash in running tap water, differentiate in $1 \%$ acid alcohol, wash again in running tap water, blue in $1 \%$ ammonia, wash again in running tap water, and rinse in $95 \%$ alcohol. After eosin counter staining, dehydrate through gradient alcohol, clear in xylene, and mount with xylene-based mounting medium.

\section{Histochemical analysis by oil red $\mathrm{O}$ staining}

For oil red O staining, cut fresh frozen tissue sections at 5-10 $\mu \mathrm{m}$ thick and mount on slides. Air dry slides for 30-60 min at room temperature and then fix in ice cold 10\% formalin for 5-10 min. Air dry again for another 30-60 min or rinse immediately in 3 changes of distilled water. Let slides air dry for a few min. Place in absolute propylene glycol for 2-5 min to avoid carrying water into Oil Red O. Stain in pre-warmed $0.5 \%$ oil red O solution $(0.5 \mathrm{~g}$ oil red $\mathrm{O}$ and $100 \mathrm{ml}$ propylene glycol) for 8-10 $\mathrm{min}$ in $60^{\circ} \mathrm{C}$ oven. Differentiate in $85 \%$ propylene glycol solution for 2-5 $\mathrm{min}$. Rinse in 2 changes of distilled water. Stain in haematoxylin for $30 \mathrm{sec}$. Wash thoroughly in running tap water for $3 \mathrm{~min}$. Place slides in distilled water. Mount with glycerin jelly.

\section{Immunohistochemical analysis}

The primary antibody against secretory leukocyte protease inhibitor (SLPI) was provided by Novus. Formalin-fixation, paraffin-embedment and deparaffinization were the same as HE staining procedure described above. Sections were incubated at room temperature with $3 \% \mathrm{H}_{2} \mathrm{O}_{2}$ to block endogenous peroxidase, and then repaired in boiling citric acid. After washing in phosphate-buffered solution, sections were blocked by $2 \%$ bovine serum albumin and incubated with $1: 100$ diluted primary antibodies at $37^{\circ} \mathrm{C}$ for $1 \mathrm{~h}$. After washing again, sections were incubated with biotinylated secondary antibodies at $37^{\circ} \mathrm{C}$ for $20 \mathrm{~min}$. After washing again, sections were incubated with diaminobenzidine for 1-5 min. After rinsing with tap water, sections were counter stained by haematoxylin. After completion of dehydration, clearance and mounting, pictures were taken under the microscope (OLYMUPUS BX-51).

\section{Electronic microscopy and spectrophotometry}


After treatment, cells were harvested and fixed in $2.5 \%$ glutaraldehyde in $0.1 \mathrm{M}$ phosphate buffer for three hours at $4{ }^{\circ} \mathrm{C}$, followed by post-fixation in $1 \%$ osmium tetroxide for one hour. Samples were dehydrated in a graded series of ethanol baths, and infiltrated and embedded in Spurr's low-viscosity medium. Ultra-thin sections of $60 \mathrm{nM}$ were cut in a Leica microtome, double-stained with uranyl acetate and lead acetate, and examined in a Hitachi 7700 transmission electron microscope at an accelerating voltage of $60 \mathrm{kV}$. The reagent kits of choline acetyltransferase (ChAT) for detection of activity and acetylcholine (ACh) for measurement of amounts were purchased from Nanjing Jiancheng Biotech Co., China. All determination procedures were according to manufacturers' instructions.

\section{Statistical analysis}

The software SPSS 22.0 was employed to analyze data, and the software GraphPad Prism 5.0 was employed to plot graphs. The Independent Simple Test was used to compare all groups, but the Kruskal-Wallis Test followed by Nemenyi test was used when the data distribution is skewed. The significance level ( $p$ value) was set at $<0.05(*),<0.01(* *),<0.001(* * *)$ and $<0.0001(* * * *)$.

\section{Results}

\section{CS induces arthritis-like synovitis and alters gut microbiota compositions in an individual dependent manner}

To verify whether a sulfate-containing nutrient might induce gut opportunistic infection through the overgrowth of some commensal bacteria, we fed AL mice daily with $25 \mathrm{mg}$ of CS each. After four weeks, CS-fed mice show either a normal phenotype or an inflammatory phenotype like synovitis, an early-phase manifestation of arthritis among CS.RA, CS.HL and CS.MN. Compared with AL1 (Fig. 1A), CS.RA exhibits erythematous and edematous paws (Fig. 1B), whereas CS.HL and CS.MN do not show any distinguishable inflammatory characters. Upon histopathological analysis, it was only noticed that one or a few layers of synovia exist in the synovial tissue of AL1 (Fig. 1C), but multi-layer intimal hyperplasia and inflammatory synovial infiltration occur in the synovial tissue of CS.RA (Fig. 1D).

To explain why CS induces different morphological changes within a same treatment group, we assumed that an inflammatory phenotype might be attributed to CS-mediated gut opportunistic infection. So we compared the gut microbiota profiles of AL and CS mice using a high-throughput 16S VX sequencing-based metagenomic analysis procedure (Additional file 2). As results illustrated in Fig. 1E, all five tested mice are dominantly inhabited by six commensal bacterial phyla, i.e., Actinobacteria, Bacteroidetes, Firmicutes, Proteobacteria, Tenericutes and Verrucomicrobia. However, a different composition of each phylum was evident among AL and CS mice. For example, CS.RA shows abundant Proteobacteria (hot/red color), including Escherichia, Polaromonas, Shewanella, Hallomonas, Paracoccus, Ralstonia, Pheudomonas, Kaistobacter and Rubellimicrobium, but rare Bacteroidetes (cold/blue color), such as Bacteroides, Prevotella, Hymenobacter and Parabacteroides. In contrast, CS.NM has more Bacteroidetes but less Proteobacteria. As to CS.HL, its phylum proportion is more similar with AL mice rather than CS mice. These findings indicated that not every mouse carries a completely identical gut microbiota community, and the gut microbiota composition would be changed or unchanged in an individual-dependent manner. 
A

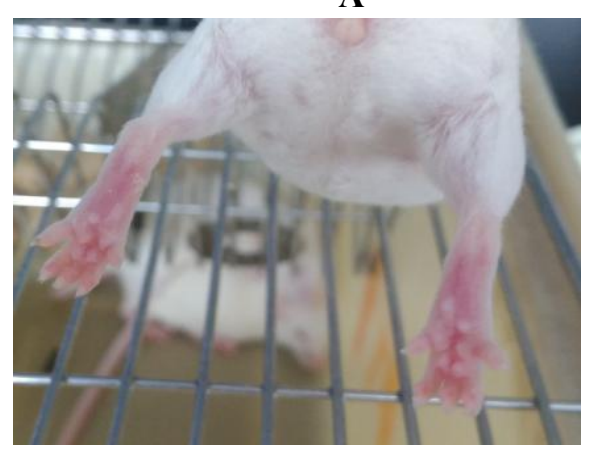

C

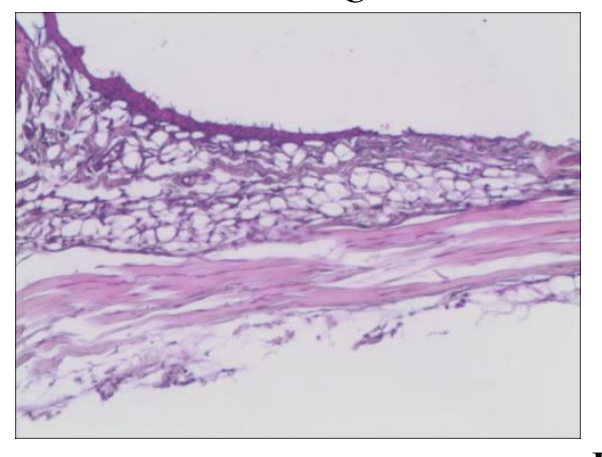

$\mathbf{E}$
B

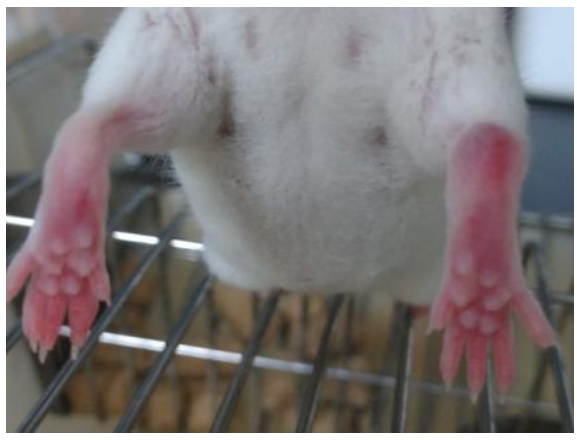

D
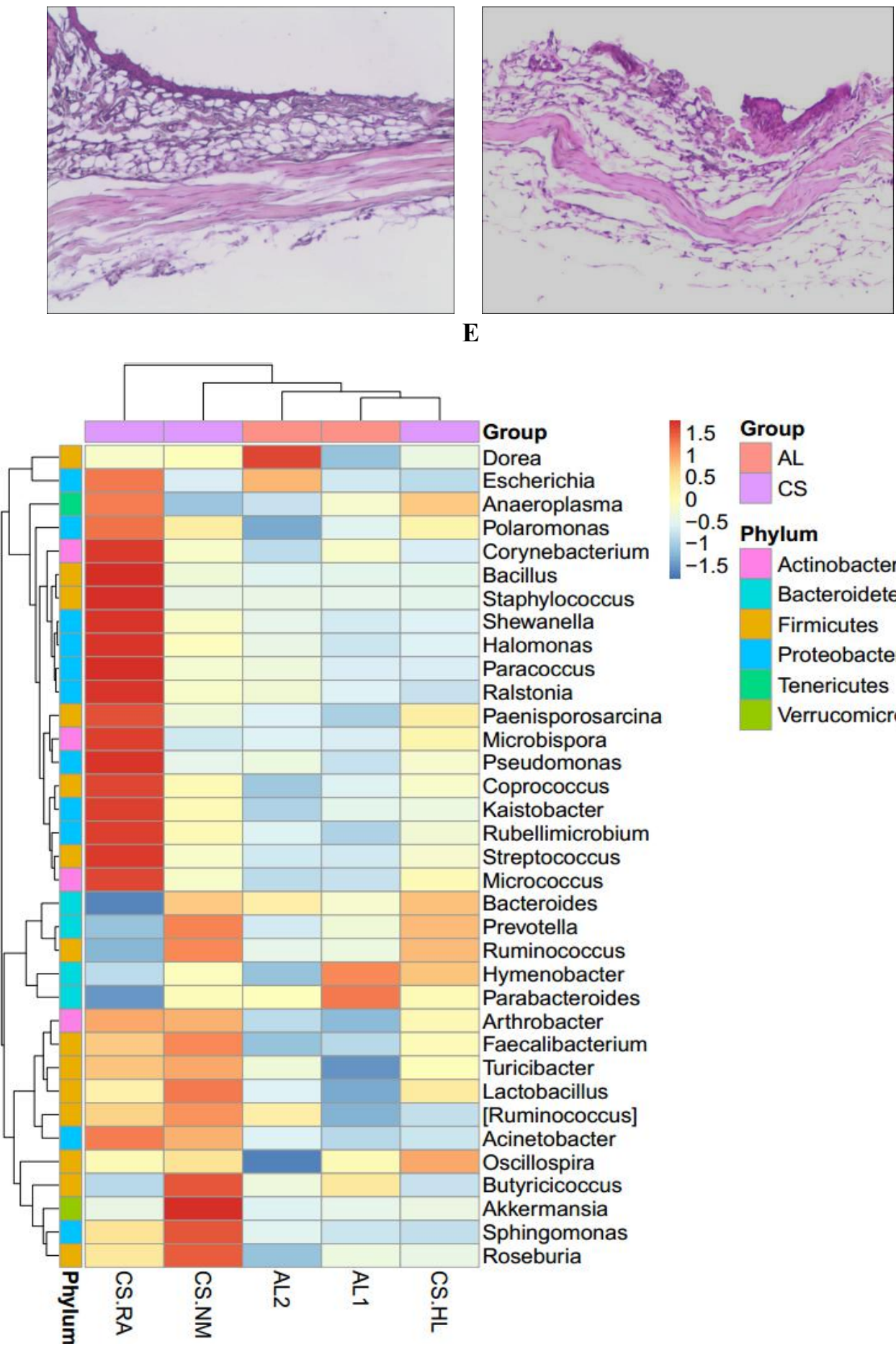

\begin{tabular}{l|l}
\hline 1.5 & Group \\
1 & AL \\
0.5 & CS \\
0 & \\
-0.5 & Phylum \\
-1 & Actinobacteria \\
-1.5 & Bacteroidetes \\
& Firmicutes \\
& Proteobacteria \\
& Tenericutes \\
& Verrucomicrobia
\end{tabular}


Fig. 1 CS-induced synovial inflammation and gut microbiota fluctuation in AL and CS mice. A. AL1 without RA-like symptoms; B. CS.RA with RA-like erythematous and edematous paws; C. HE staining of synovial tissues of AL1; D. HE staining of synovial tissues of CS.RA; E. The relative abundance of bacterial phyla in the gut of $A L$ and CS mice, in which the cold and hot colors represent $Z$ values from -1.5 to 1.5 .

The abundant microbiota in the gut of CS.RA belongs to nine genera of Gram-negative Proteobacteria and five genera of Gram-positive Firmicutes, which represent two largest bacterial phyla containing SSB and SRB. As listed in Table 1, one of the SSB species B. cereus from Firmicutes is extraordinarily enriched in the gut of CS.RA (4.03\%), and another SSB species $A$. muciniphila is extremely enriched in CS.NM (4.00\%). In average, CS mice not only possess more SSB than AL mice ( $1.655 \%$ vs $0.27 \%$ ), but also carry more SRB than AL mice ( $1.23 \%$ vs $0.86 \%)$. Therefore, SSB should have nourished SRB by degrading CS and cellular sulfate components such as mucin to provide sulfate as an electric recipient for reduction of sulfate to hydrogen sulfide $\left(\mathrm{H}_{2} \mathrm{~S}\right)$.

Table 1 Classification of SSB and SRB in the gut microbiota of AL and CS mice

\begin{tabular}{llccccccc}
\hline & AL1 & AL2 & $\overline{\mathrm{x}} \pm \mathrm{S}$ & CS.RA & CS.HL & CS.NM & $\overline{\mathrm{x}} \pm \mathrm{S}$ \\
& & $(\%)$ & $(\%)$ & $(\%)$ & $(\%)$ & $(\%)$ & $(\%)$ & $(\%)$ \\
\hline \multirow{2}{*}{ SSB } & A. muciniphila & 0.40 & 0.20 & $0.30 \pm 0.14$ & 0.50 & 0.50 & 4.00 & $1.67 \pm 2.02$ \\
\cline { 2 - 9 } & B. cereus & 0.24 & 0.24 & $0.24 \pm 0.00$ & 4.03 & 0.65 & 0.24 & $1.64 \pm 2.08$ \\
\hline \multirow{2}{*}{ SRB } & Desulfovibrionaceae & 0.97 & 0.75 & $0.86 \pm 0.16$ & 1.31 & 1.08 & 1.30 & $1.23 \pm 0.13$ \\
\hline
\end{tabular}

These results indicated that CS-induced overgrowth of SSB and SRB might depend on a "food chain", where SSB secrete sulfatase for degradation of CS and mucin, and SRB reduce sulfate to $\mathrm{H}_{2} \mathrm{~S}$. While CS nourishes B. cereus and Desulfovibrionaceae in CS.RA, it alternatively nourishes A. muciniphila and Desulfovibrionaceae in CS.NM. Unfortunately, we did not know whether CS mice prior to CS feeding have the same gut microbiota with AL mice although AL1 and AL2 harbor the identical or similar SSB and SRB. Following mucin degradation, the intestinal integrity would be compromised, thereby leading to LPS leaking out from the gut and entering into the blood stream.

\section{CS elevates LPS and TNF- $\alpha$ levels and upregulates dementia and arthritis hallmarks}

To ravel whether gut opportunistic infection might lead to LPS entry into the circulation, we determined the serum level of LPS in AL and CS mice. In consequences, CS.RA shows not only a higher serum level of LPS than AL1 (16.18 U/L vs $11.96 \mathrm{U} / \mathrm{L})$, but also an elevated serum levels of the dementia marker PS-1 (144.15 pg/ml) and the arthritis marker RF (32.44 U/L) as compared to AL1 $(80.82 \mathrm{pg} / \mathrm{ml}$ and $30.89 \mathrm{U} / \mathrm{L})$, hinting that CS might have initiated a pathogenic process towards dementia and arthritis. In similar, both serum and brain TNF- $\alpha$ levels are synchronously elevated in CS.RA, suggesting systemic and neuroinflammatory responses (Table 2).

Table 2 Comparison of LPS, PS-1, RF, and TNF- $\alpha$ levels between AL and CS mice

\begin{tabular}{lcccccccc}
\hline \multicolumn{1}{c}{ Tests } & AL1 & AL2 & AL3 & $\overline{\mathrm{x}} \pm \mathrm{s}$ & CS.RA & CS.NM & CS.HL & $\overline{\mathrm{x}} \pm \mathrm{s}$ \\
\hline $\begin{array}{l}\text { Serum LPS } \\
(\mathrm{U} / \mathrm{L})\end{array}$ & 11.96 & 14.94 & 16.64 & $14.51 \pm 1.93$ & 16.18 & 16.09 & 13.29 & $15.19 \pm 1.64$ \\
\hline $\begin{array}{l}\text { Serum PS-1 } \\
(\mathrm{pg} / \mathrm{ml})\end{array}$ & 80.82 & 220.59 & 159.44 & $153.61 \pm 70.07$ & 144.15 & 116.64 & 133.67 & $131.49 \pm 13.88$ \\
\hline Serum RF & & & & & & & & \\
\hline
\end{tabular}




\begin{tabular}{lllllllll}
\hline$(\mathrm{U} / \mathrm{L})$ & & & & & & & \\
\hline $\begin{array}{l}\text { Serum TNF- } \alpha \\
(\mathrm{ng} / \mathrm{L})\end{array}$ & 378.73 & 526.25 & 763.2 & $556.06 \pm 193.96$ & 1067.18 & 407.87 & 664.67 & $713.24 \pm 332.33$ \\
\hline $\begin{array}{l}\text { Brain TNF- } \alpha \\
(\mathrm{ng} / \mathrm{L})\end{array}$ & 513.50 & 611.85 & 881.40 & $668.92 \pm 190.47$ & 1150.96 & 569.96 & 741.16 & $820.69 \pm 298.55$ \\
\hline
\end{tabular}

To make sure if $\mathrm{CS}$ is exactly implicated in dementia induction by triggering neuroinflammation, we further measured the cerebral levels of A $\beta$, PS-1, LPS, and TNF- $\alpha$ in AL1 and CS.RA. Surprisingly, A $\beta$ and TNF- $\alpha$ levels are elevated (Fig. 2A-2B), whereas LPS and PS-1 levels are declined in CS.RA (Fig. 2C-2D). For this result, we proposed that LPS and PS-1 levels should be converted from high levels to low ones. Indeed, we detected high serum LPS and PS-1 levels in CS mice (see Table 2). So we assumed a mechanism underlying that eradication of LPS and subsequent downregulation of PS- 1 are driven by anti-LPS antibodies, during which A $\beta$ and TNF- $\alpha$ are participated in activation of the immune system.

Furthermore, we evaluated the functional changes in the brain by determining the cerebral $\mathrm{TH}$, Ach and ChAT levels. Consequently, the cerebral level of TH, a rate-limiting enzyme for biosynthesis of the anti-inflammatory neurotransmitter dopamine, is lower in CS.RA than in AL1 (Fig. 2E), suggesting an attenuated anti-inflammatory ability in the brain of CS.RA. Accordingly, the cerebral levels of the cholinergic neurotransmitter Ach and its rate-limiting biosynthetic enzyme ChAT are also lower in CS.RA than in AL1 (Fig. 2F and 2G), implying a compromised neuronal function and a progressed cognitive deficit in CS.RA. It was also seen from Fig. $2 \mathrm{H}$ that the relative autophagy-inactivating LC3-1 level is higher than the relative autophagy-activating LC3-2 in CS.RA than AL1, highlighting that the autophagic functions are attenuated in CS.RA.

A

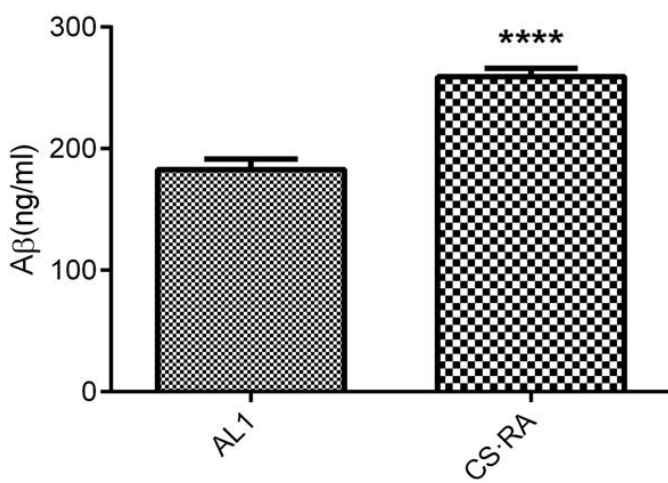

C

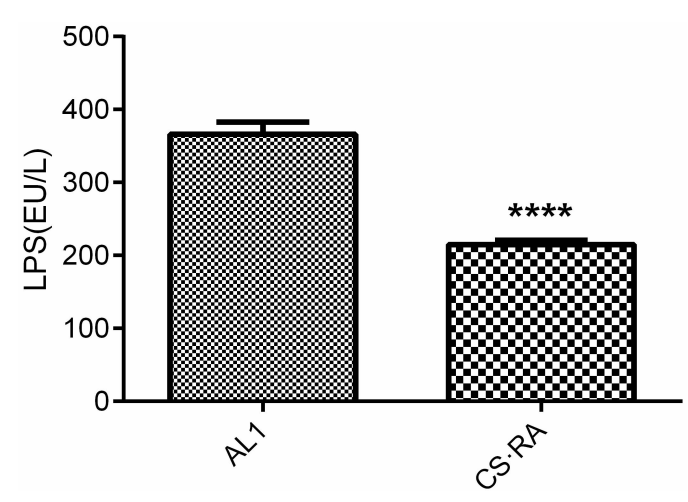

B

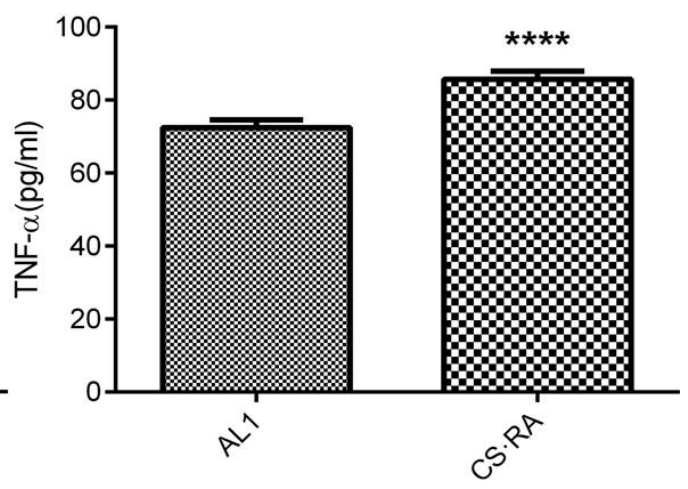

D

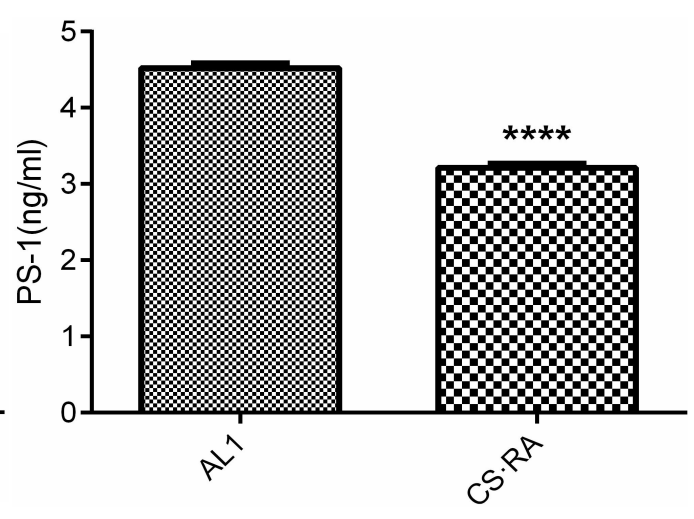

E 


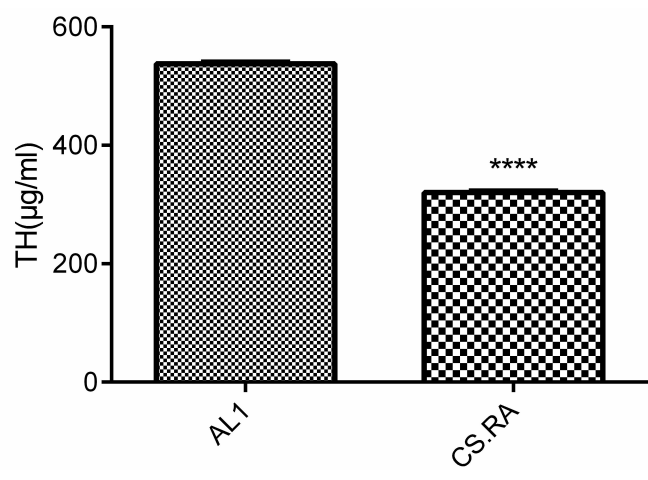

$\mathbf{F}$

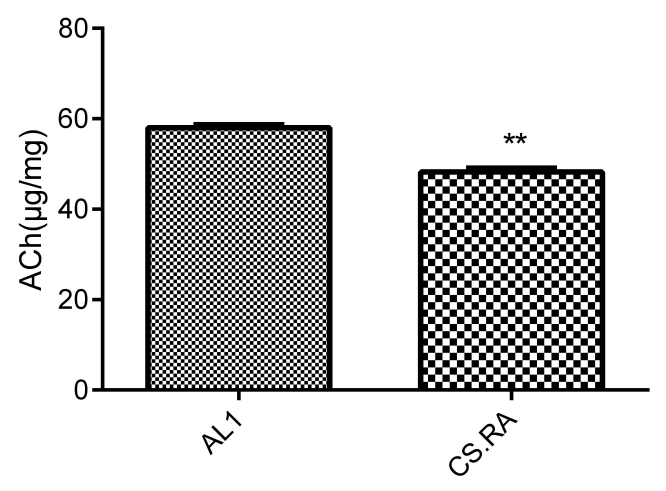

G

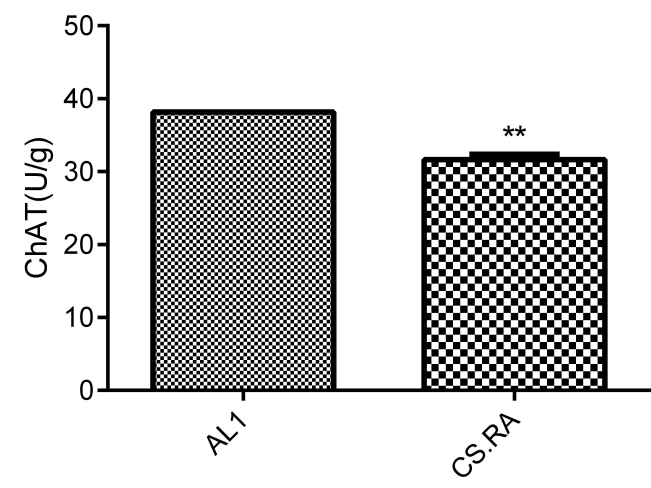

H

AL1 CS.RA

LC3-2

LC3-1

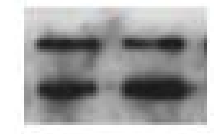

GAPDH

Fig. 2 Expression of inflammatory and pathogenic markers in the cerebral tissues of AL1 and CS.RA mice. A. A levels. B. TNF- $\alpha$ levels. C. LPS levels. D. PS-1 levels. E. TH levels; F. Ach levels; G. ChAT levels. H. LC3-2/1. ${ }^{* * *} p<0.0001$. ${ }^{* * *} p<0.001$.

\section{CS induces pro/anti-inflammatory responses in a tissue specific pattern}

To further elucidate whether the circulated LPS would trigger systemic inflammation, we determined the levels of pro-inflammatory and anti-inflammatory markers in different organs and tissues. As compared to AL1, CS.RA exhibits an elevated TNF- $\alpha$ level in hepatic and muscular tissues, but a declined TNF- $\alpha$ level in adipose tissues (Fig. 3A). Intriguingly, LPS levels in three tested organs are all lower in CS.RA than in AL1 (Fig. 3B). For the lower TNF- $\alpha$ level seen in the adipose tissue of CS.RA, we assumed that it might experience a conversion from a high level to low one.

Evidence supporting this assumption is available from the comparison of TNFR1 levels among the adipose, hepatic and muscular tissues of AL1 and CS.RA mice. As illustrated in Fig. 3C, TNFR1 levels are higher in the adipose tissue, implying that LPS induces TNF- $\alpha$ at first, then TNF- $\alpha$ activates TNFR1, and TNFR1-transduced signaling finally depletes LPS in the adipose tissue. The LPS-binding receptor TLR4 is upregulated in the hepatic and cardiac tissues, but unchanged in the adipose tissue of CS.RA (Fig. 3D). At the same time, the signaling chemokine CCL2 is upregulated in the cardiac tissue, and unchanged in the hepatic tissue, or downregulated 
in the adipose tissue of CS.RA (Fig. 3E). These results seemed to address that adipose tissues proceed a conversion from a pro-inflammatory phase to an anti-inflammatory phase, but other tissues are maintained in a pro-inflammatory status.

A

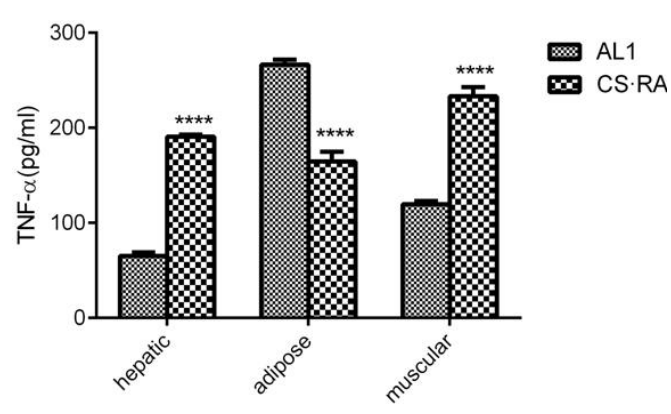

B

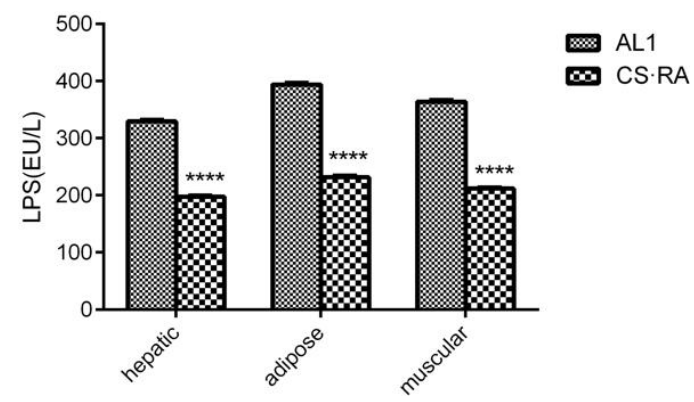

C

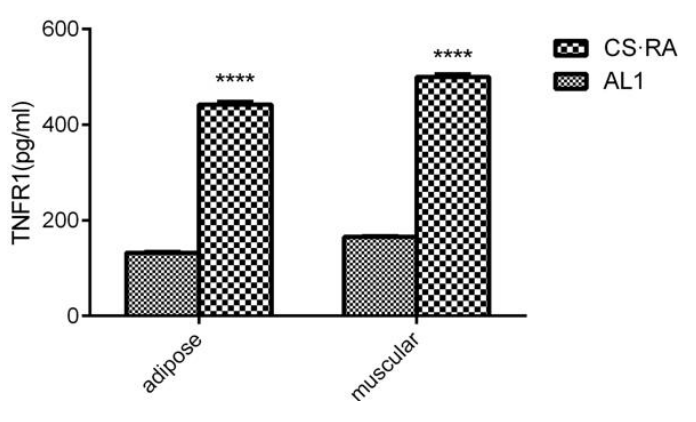

D

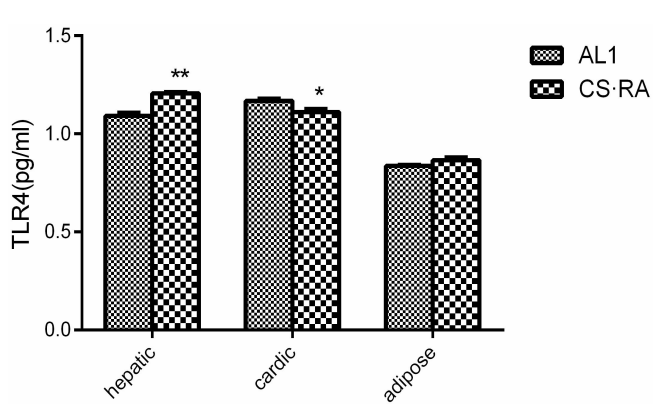

$\mathbf{E}$

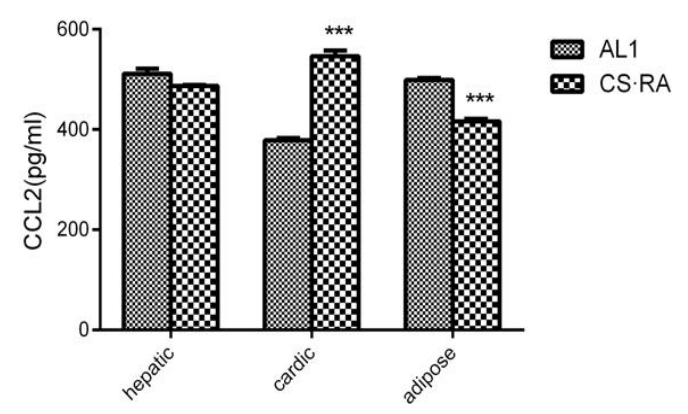

Fig. 3 Pro/anti-inflammatory responses to CS-driven gut dysbiosis in different tissues of AL1 and CS.RA mice. A. TNF- $\alpha$ levels in adipose, hepatic and muscular tissues. B. LPS levels in adipose, hepatic and muscular tissues. C. TNFR levels in adipose and muscular tissues. D. TLR4 levels in hepatic, cardiac and adipose tissues. E. CCL2 levels in hepatic, cardiac and adipose tissues. ${ }^{* * * *} p<0.0001$. ${ }^{* * *}$ $p<0.001 .{ }^{* *} p<0.01 .^{*} p<0.05$.

\section{CS induces sulfatase secretion and mucin degradation accompanying with enhanced SLPI and MUC1/MUC4 expression}

Although CS was shown to augment the selective inflammatory and pathogenic signatures, data listed above were available only on an individual basis. Therefore, we enlarged the scale of tested samples for further verification. To ascertain CS-induced inflammation and pathogenesis are resulted from SSB overgrowth and sulfatase overproduction, we quantified the mRNA levels of sulfatase of SSB and ATP sulfurylase of SRB in the fecal samples of AL and CS mice (Table 3). However, no difference of average values was observed between AL and CS mice.

Table 3 The relative copy numbers of sulfatase or ATP sulfurylase mRNAs in AL and CS mice $(n=5)$ 


\begin{tabular}{cccccc}
\hline & Sulfatase & Sulfatase 1 & Sulfatase 2 & T-sulfatase & ATP sulfurylase \\
\hline $\mathrm{AL}$ & $1.60 \pm 1.466$ & $1.08 \pm 0.274$ & $1.15 \pm 0.303$ & $1.23 \pm 0.313$ & $1.41 \pm 0.580$ \\
\hline $\mathrm{CS}$ & $1.45 \pm 0.669$ & $1.12 \pm 0.278$ & $1.28 \pm 0.379$ & $1.56 \pm 0.837$ & $1.45 \pm 0.674$ \\
\hline
\end{tabular}

Note: Sulfatase exists in $B$. cereus. Sulfatase $1 / 2$ exists in $A$. muciniphila. T-sulfatase exists in $B$.

thetaiotaomicron; and ATP sulfurylase exists in $D$. desulfuricans.

Because each mouse has a unique array of the gut microbiota, it should not be compared with the average levels of sulfate-degrading enzymes. Given that the lowest mRNA levels of sulfatases represent the less abundant SSB, and the highest mRNA levels of sulfatases represent the much abundant SSB, it should be compared on an individual basis. As consequences, all tested sulfatases are significantly upregulated in a CS mouse as compared with an AL mouse (Fig. 4). Interestingly, it was obviously that CS2 and CS3 show the higher sulfatase levels than other mice. While t-sulfatase mRNA of $B$. thetaiotaomicron shows the highest level in CS2, sulfatase mRNA of $B$. cereus and sulfatase $1 \mathrm{mRNA}$ of $A$. muciniphila shows the highest levels in CS3. Actually, the level of sulfatase 2 mRNA of $A$. muciniphila is also higher in CS3, only slightly lower than that in CS4.

A

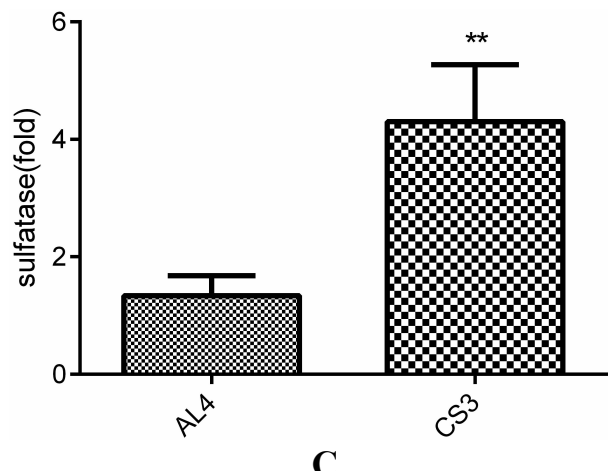

C

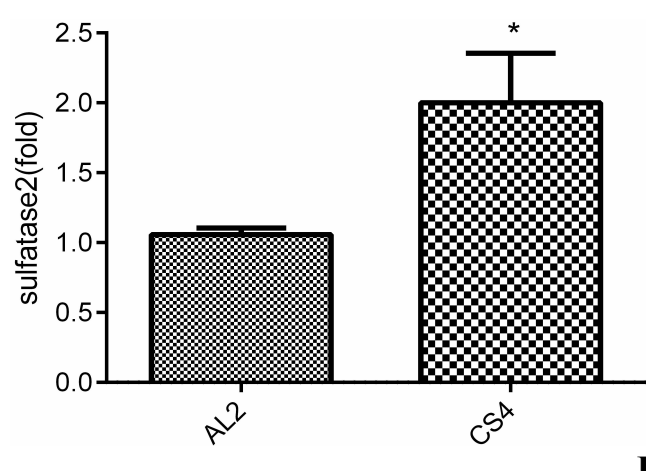

B

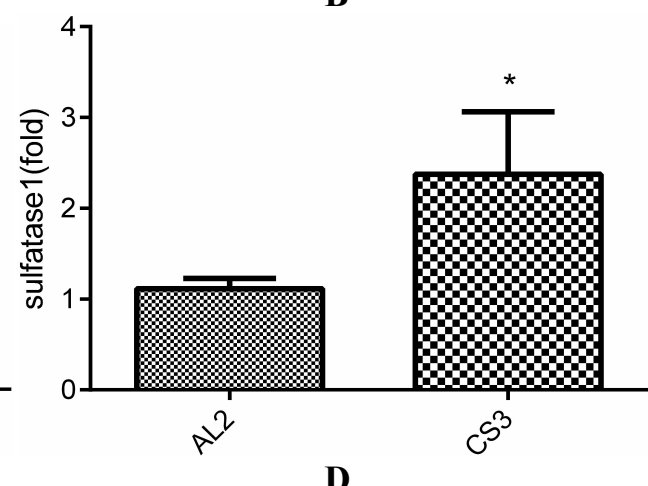

D

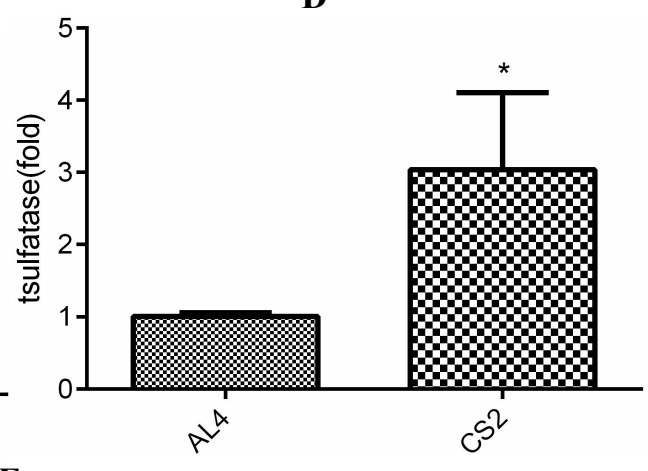

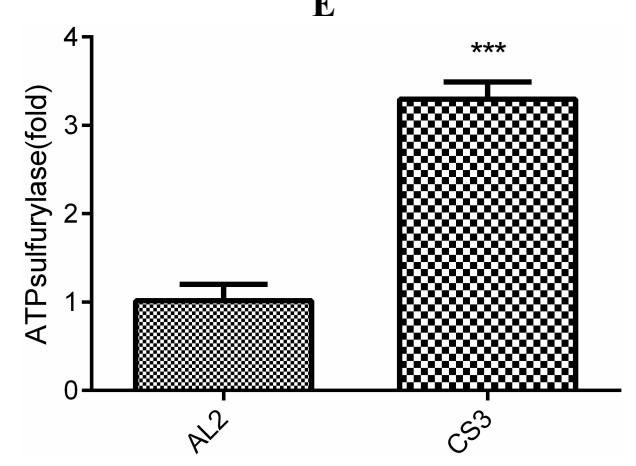

Fig. 4 Expression of bacterial sulfatases and ATP sulfurylase in the gut microbiota of AL and CS mice. A. sulfatase mRNA levels in B. cereus. B. sulfatase 1 mRNA levels in A. muciniphila. C. sulfatase 2 mRNA levels in $A$. muciniphila. D. T-sulfatase mRNA levels in $B$. thetaiotaomicron. E. ATP sulfurylase mRNA levels in $D$. desulfuricans. ${ }^{* *} p<0.001 .{ }^{* *} p<0.01 .{ }^{*} p<0.05$. 
Once mucin is degraded, SLPI should be upregulated because of mucus damage. As compared with AL2 (Fig. 5A), SLPI is remarkably upregulated in CS2 (Fig. 5B) and CS3 (Fig. 5C). Interestingly, as shown in Fig. 4, CS2 shows overexpression of sulfatase in B. thetaiotaomicron, and CS3 exhibits the high levels of sulfatase in B. cereus and sulfatase $1 / 2$ in A. muciniphila, indicating an association of high sulfatase levels with enhanced SLPI expression. On the other hand, mucus damage should be also anticipated to upregulate MUC1/MUC4 for mucus repairing. Indeed, it was noticed that MUC1 is upregulated in CS3 and CS4, while MUC4 is upregulated in CS1, CS2 and CS3 (Fig. 5D). Unexpectedly, MUC1 and MUC4 are upregulated in AL3 with an unknown reason.

A

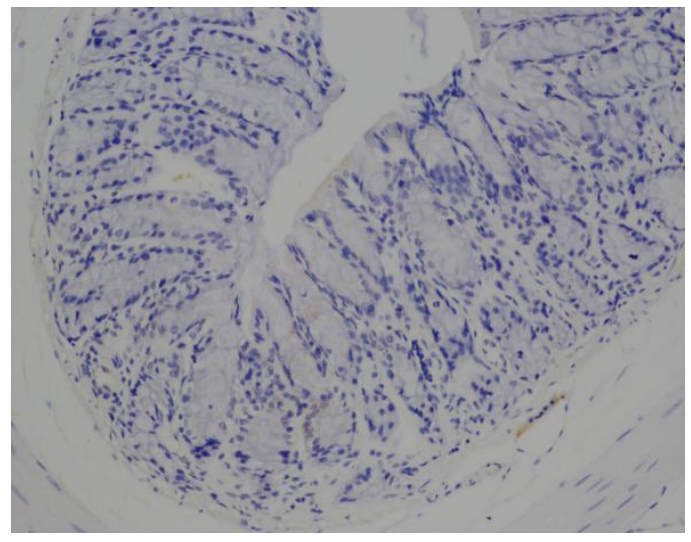

C

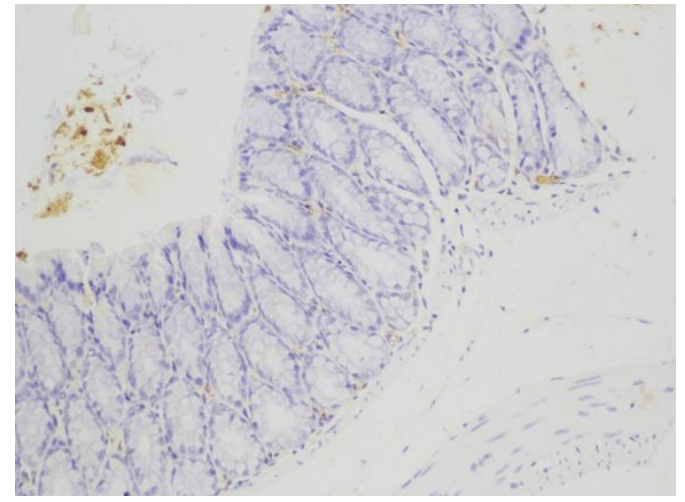

B

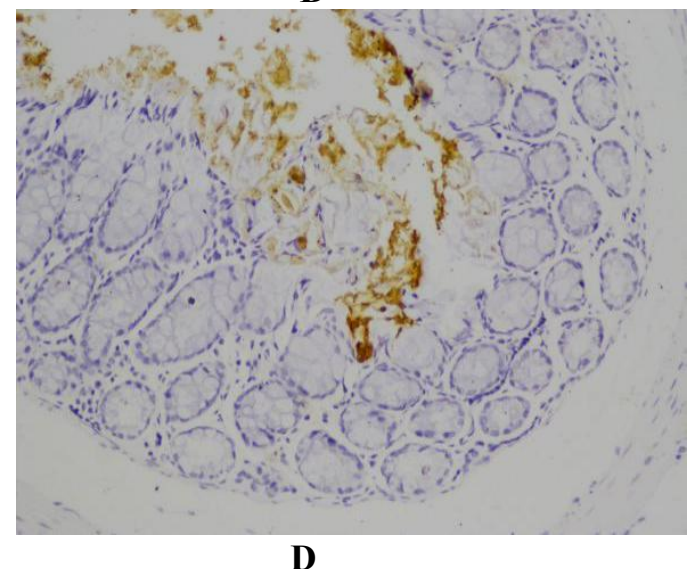

AL

CS

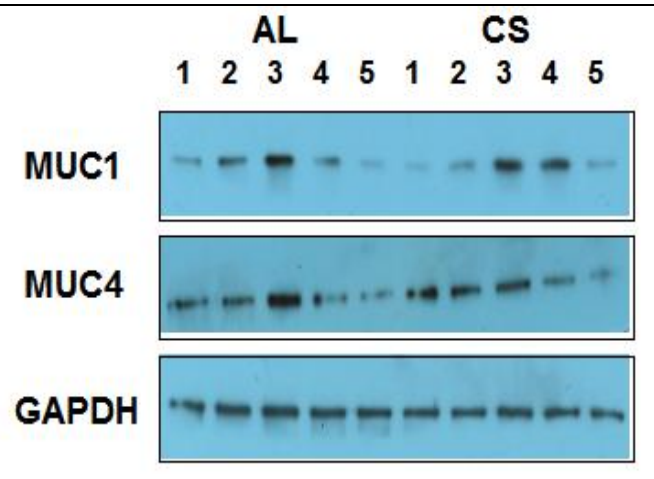

Fig. 5 Mucus impairment and mucin expression in AL and CS mice. A. SPLI in the gut of AL2. B. SPLI in the gut of CS2. C. SPLI in the gut of CS3. D. MUC1/4 levels in AL and CS mice.

\section{CS induces tumor-like hyperplasia and tumor marker expression followed by a systemic pro-inflammatory response}

During the large-scale evaluation of CS-induced pro-inflammatory responses, we unexpectedly observed a tumor-like hyperplasic object in the inner chest of a CS mouse (Fig. 6A). As compared with the circumjacent muscular tissues, the tumor marker CD1 shows a higher level in the neoplasm, whereas the tumor suppressor p21 exhibits a lower level in the neoplasm (Fig. 6B).

To dissect the inflammatory profiles in this mouse carrying a neoplasm, we measured LPS and TNF- $\alpha$ levels in different tissues and the neoplasm per se. Intriguingly, LPS shows decline in hepatic and cardiac tissues, but elevation in adipose tissues (Fig. 6C). In similar, TNF- $\alpha$ is also declined in all tested tissues except for adipose tissues (Fig. 6D). Surprisingly, both LPS and TNF- $\alpha$ exhibit lower levels in the neoplasm. These results indicated that pro/anti-inflammation is differentially modulated in an organ-dependent manner, during which LPS and TNF- $\alpha$ in adipose 
tissues demonstrate a conversion from lower levels to higher ones, whereas those in other tissues also present a dynamic change from higher levels to lower ones.

To further address an association of CS, SSB, LPS and tumorigenesis, we quantified the mRNA levels of three breast cancer-related markers, in the female mice fed with CS and intragastrically inoculated with $B$. cereus, or only intramuscularly injected with LPS. Consequently, the levels of $R U N X 1, T P 53 B P 1$ and BCL11A mRNA as breast cancer markers are highly elevated in the mammary tissues of tested CS-BC and LPS mice (Fig. 6E-6G). These results indicated that SSB feeding or LPS administering can lead to the onset of mammalian tumorigenesis.

A

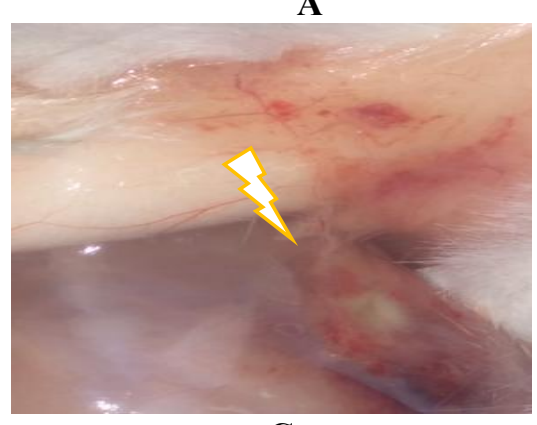

C

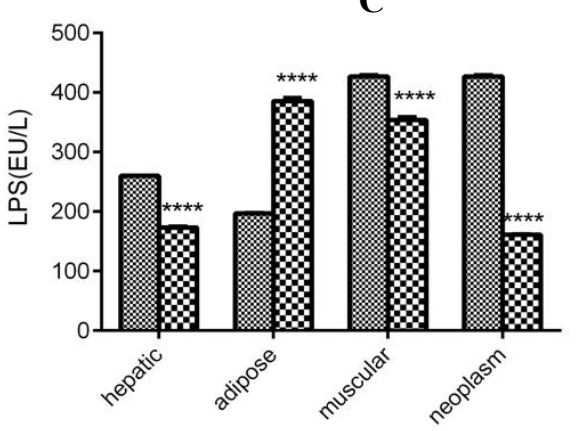

$\mathbf{E}$

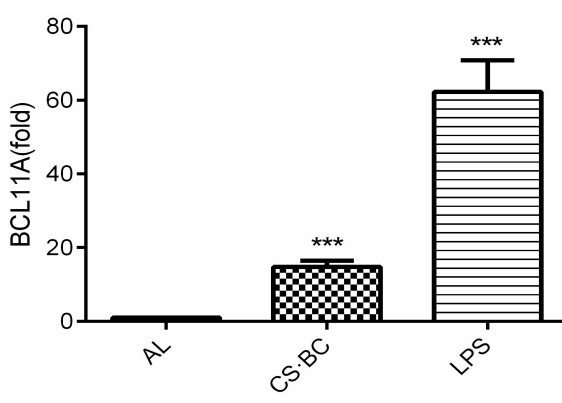

B
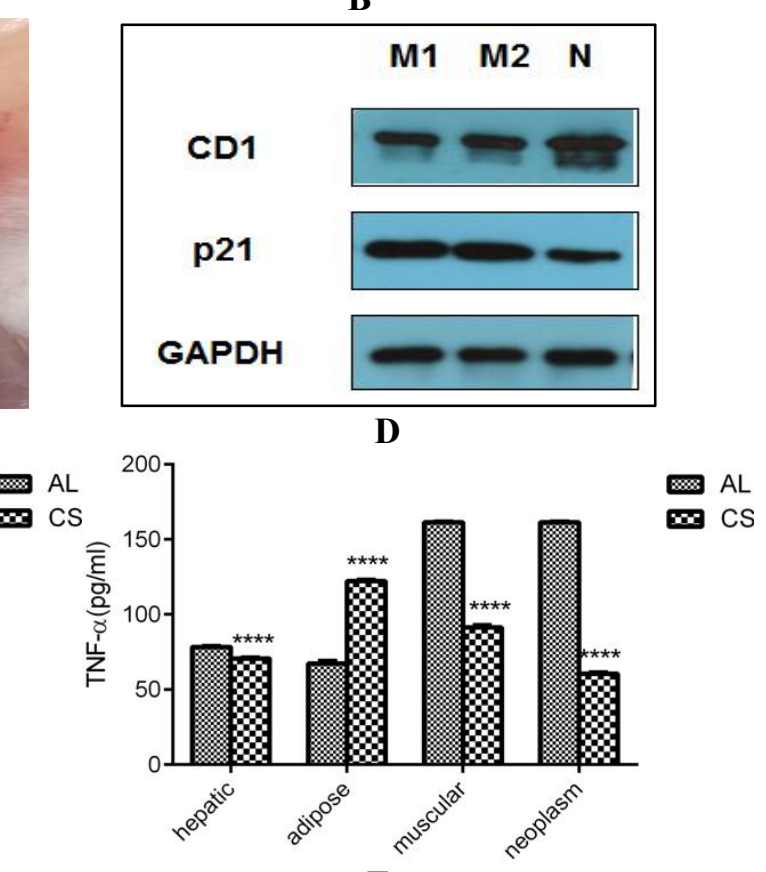

$\mathbf{F}$

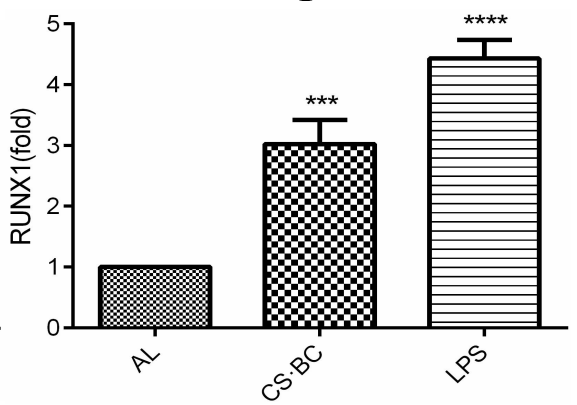

G

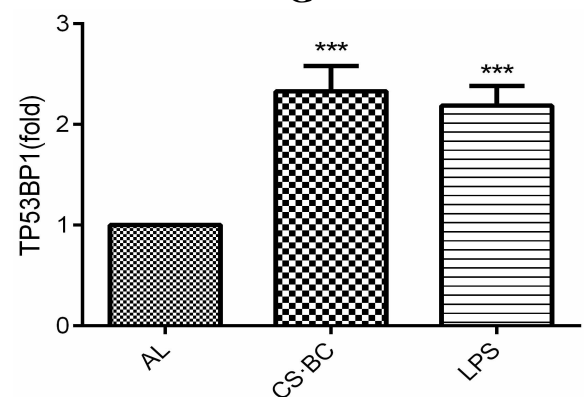

Fig. 6 CS-induced tumor-like hyperplasia and tumor marker expression in AL, CS, CS-BC and LPS mice. A. Phenotypical morphology of tumor-like neoplasm. B. CD1 and p21 levels in the neoplasm, in which $\mathrm{M} 1 / \mathrm{M} 2$ represents muscular tissues, and $\mathrm{N}$ represents a neoplasm sample. C. LPS levels in hepatic, adipose, muscular tissues and the neoplasm. D. TNF- $\alpha$ levels in hepatic, adipose, muscular tissues and the neoplasm. C-E. RUNX1, TP53BP1 and BCL11A mRNA levels in mammary tissues. ${ }^{* * \star *}$ $p<0.0001 .{ }^{* * *} p<0.001$. 


\section{CS regulates hypoxia, angiogenesis and mitochondrial biogenesis biomarkers}

To explore whether inflammation would activate iNOS and HIF-1 $\alpha$ to initiate the expression of downstream hypoxia-sensing genes, we measured the mRNA levels of iNOS, HIF-1 $\alpha$, VEGF and EPO in AL and CS mice. As depicted in Fig. 7A-7D, iNOS, HIF-1 $\alpha$, VEGF and EPO are upregulated in adipose tissues, but downregulated in the neoplasm of CS mice, suggesting adipose tissues in a pro-inflammatory status, but the neoplasm in an anti-inflammatory period. As an essential anti-inflammatory outcome, iNOS, HIF-1 $\alpha$, VEGF and EPO are downregulated globally in other tissues of CS mice.

On the other hand, CYCS and MFN2, as two mitochondrial biomarkers, are also differentially modulated in CS mice. As compared to AL mice, CSCS is downregulated in CS hepatic and adipose tissues, but unchanged in CS cardiac tissues (Fig. 7E). In contrast, MFN2 is upregulated in hepatic tissues, but unchanged in CS cardiac and adipose tissues (Fig. 7F). Those results derived from the adipose tissues suggested a compromised capacity of mitochondrial biogenesis that reflects a pro-inflammatory state in CS mice.

A

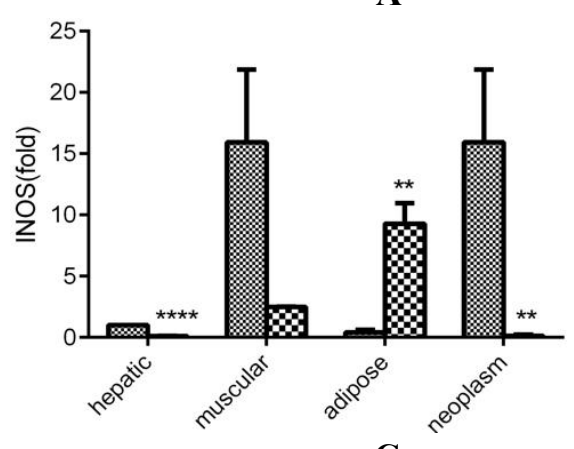

C

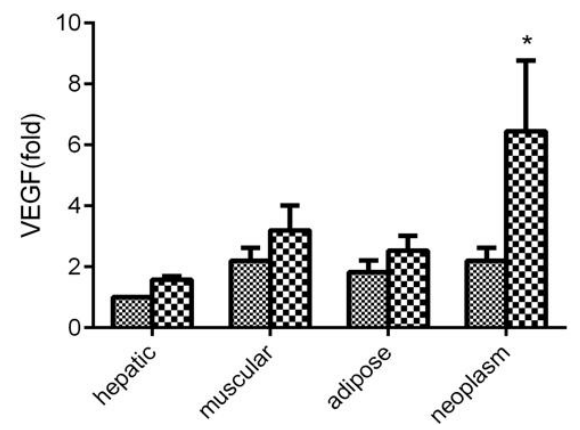

$\mathbf{E}$

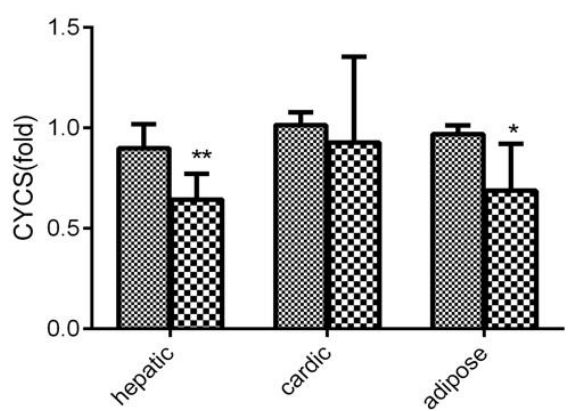

B
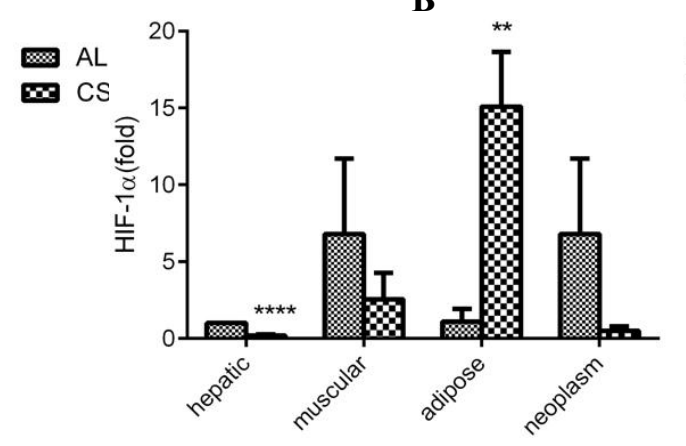

D

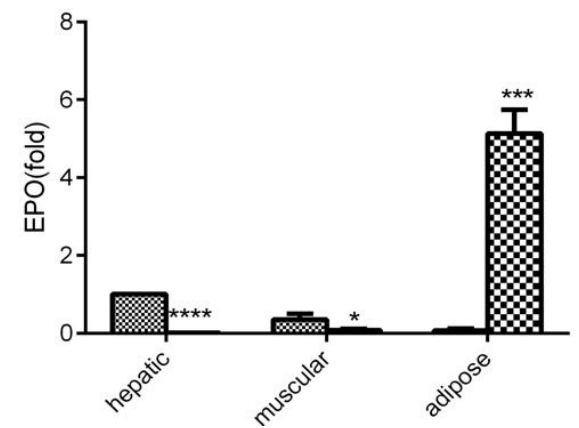

F

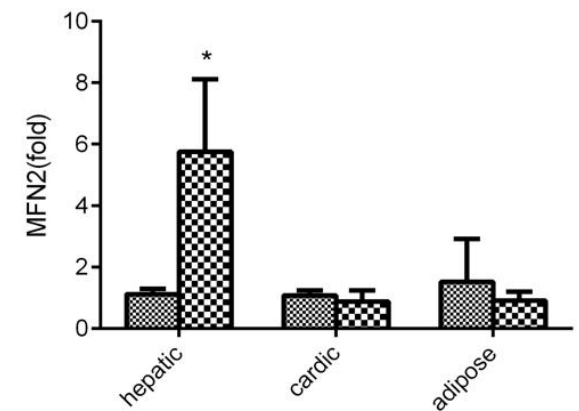

Fig. 7 NO-driven hypoxic responses and mitochondrial biogenesis in different tissues and neoplasm of AL and CS mice. A. iNOS mRNA levels. B. HIF-1a mRNA levels. C. EPO mRNA levels. D. VEGF mRNA levels. E. CYCS mRNA levels. F. MFN2 mRNA levels. ${ }^{* \star *} p<0.0001 .{ }^{* \star *} p<0.001 .{ }^{* *} p<0.01 .{ }^{*} p<0.05$.

CS-triggered inflammation induces fatty liver-related gene expression and fatty liver-like lipogenesis 
To link CS-leaked LPS to hepatosteatosis and NALFD, we evaluated the expression profiles of 84 genes related to the pathogenesis to fatty liver in LPS-injected mice (Additional file 3).

Consequently, genes for inflammatory responses and metabolic/signaling pathways were noticed to upregulation in the hepatic sample from a CS mouse (Table 4). For example, IL-1 $\beta$ is increased for 94 folds, IL-10 is increased for 50 folds, and IL-6 and TNF are increased for 12 and 10 folds. These results imply that hepatic inflammation might initiate a pathogenic process toward hepatosteatosis. Notably, carbohydrate metabolism responsible PDK4 and cholesterol metabolism/transport responsible ABCG-1 and CYP2E1 are increased for 21, 27 and 34 folds, respectively, hinting a trend towards NALFD.

Table 4 The hepatic expression levels of NAFLD-related genes with up/downregulation for more than two folds in AL and LPS mice

\begin{tabular}{|c|c|c|c|}
\hline Pathway/Metabolism & Gene & Description & $\begin{array}{c}\text { Fold regulation } \\
\text { of LPS to AL }\end{array}$ \\
\hline \multirow{6}{*}{$\begin{array}{l}\text { Inflammatory } \\
\text { response }\end{array}$} & Cebpb & CCAAT/enhancer binding protein (C/EBP), beta & 2.50 \\
\hline & Ifng & Interferon gamma & 5.52 \\
\hline & I/10 & Interleukin 10 & 50.20 \\
\hline & $/ / 1 b$ & Interleukin 1 beta & 94.24 \\
\hline & 116 & Interleukin 6 & 12.54 \\
\hline & Tnf & Tumor necrosis factor & 10.24 \\
\hline \multirow{6}{*}{$\begin{array}{l}\text { Carbohydrate } \\
\text { metabolism }\end{array}$} & G6pc & Glucose-6-phosphatase, catalytic & 3.64 \\
\hline & G6pdx & Glucose-6-phosphate dehydrogenase X-linked & 3.27 \\
\hline & Pck2 & Phosphoenolpyruvate carboxykinase 2 (mitochondrial) & 2.45 \\
\hline & Pdk4 & Pyruvate dehydrogenase kinase, isoenzyme 4 & 21.27 \\
\hline & Pklr & Pyruvate kinase liver and red blood cell & -7.02 \\
\hline & Rbp4 & Retinol binding protein 4 , plasma & 2.65 \\
\hline \multirow[t]{2}{*}{$\beta$-oxidation } & Acox1 & Acyl-coenzyme A oxidase 1, palmitoyl & 2.13 \\
\hline & Cpt1a & Carnitine palmitoyltransferase $1 \mathrm{a}$, liver & 2.72 \\
\hline \multirow{8}{*}{$\begin{array}{l}\text { Cholesterol } \\
\text { metabolism/transport }\end{array}$} & Abca1 & ATP-binding cassette, sub-family $A(A B C 1)$, member 1 & 6.48 \\
\hline & Abcg1 & ATP-binding cassette, sub-family G (WHITE), member 1 & 27.10 \\
\hline & Apoa1 & Apolipoprotein A-I & 2.83 \\
\hline & Apob & Apolipoprotein B & 6.97 \\
\hline & Apoe & Apolipoprotein E & 2.97 \\
\hline & Cd36 & CD36 antigen & 2.37 \\
\hline & Cyp2e1 & Cytochrome P450, family 2, subfamily e, polypeptide 1 & 34.38 \\
\hline & Nr1h3 & Nuclear receptor subfamily 1 , group $\mathrm{H}$, member 3 & 3.39 \\
\hline \multirow{3}{*}{$\begin{array}{l}\text { Insulin signaling } \\
\text { pathway }\end{array}$} & $\operatorname{lgf1}$ & Insulin-like growth factor 1 & 3.19 \\
\hline & Ptpn1 & Protein tyrosine phosphatase, non-receptor type 1 & 3.14 \\
\hline & Socs3 & Suppressor of cytokine signaling 3 & 7.18 \\
\hline \multirow{5}{*}{$\begin{array}{l}\text { Adipokine signaling } \\
\text { pathway }\end{array}$} & Cd36 & CD36 antigen & 2.37 \\
\hline & Lepr & Leptin receptor & -2.60 \\
\hline & Serpine1 & Serine (or cysteine) peptidase inhibitor, clade $\mathrm{E}$, member 1 & 3.67 \\
\hline & Slc2a1 & Solute carrier family 2 , member 1 & 2.11 \\
\hline & Stat3 & Signal transducer and activator of transcription 3 & 2.00 \\
\hline
\end{tabular}


bioRxiv preprint doi: https://doi.org/10.1101/145714; this version posted June 3, 2017. The copyright holder for this preprint (which was not certified by peer review) is the author/funder, who has granted bioRxiv a license to display the preprint in perpetuity. It is made available under aCC-BY-NC 4.0 International license.

During evaluation of CS impacting on lipid accumulation (lipogenesis) or lipid degradation (lipolysis), we tried to observe whether oil deposits exist in the oil red-stained hepatic tissues. As compared with the hepatic sample from an AL mouse (Fig.8A), a large number of condensed oil droplets were seen in that from an CS mouse (Fig.8B). Accordingly, mitochondria that can degrade fatty acids via the Krebs cycle are extensively decreased in their numbers and sizes, which were distinguishable in muscular tissues (Fig. 8C and Fig. 8D) and adipose tissues (Fig. 8E and $8 \mathrm{~F}$ ) by less mitochondria and more oil droplets. These results suggested that systemic inflammation might have led to mitochondrial deficiency and metabolic dysfunction, by which impedes lipid catabolism and enhances lipid deposits.

A

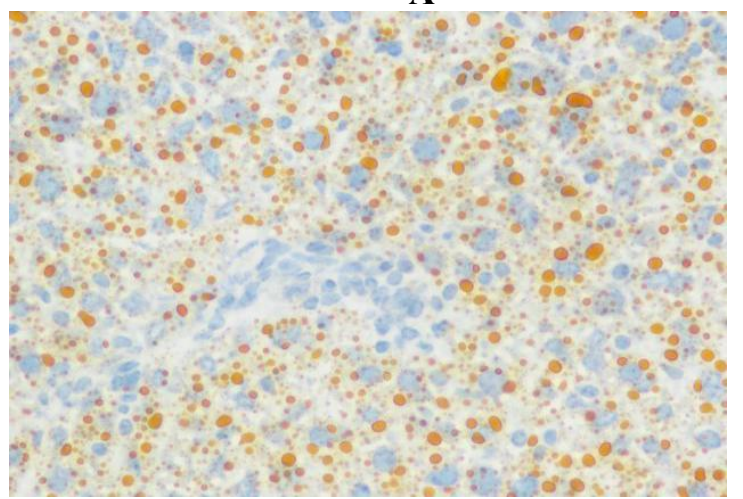

C

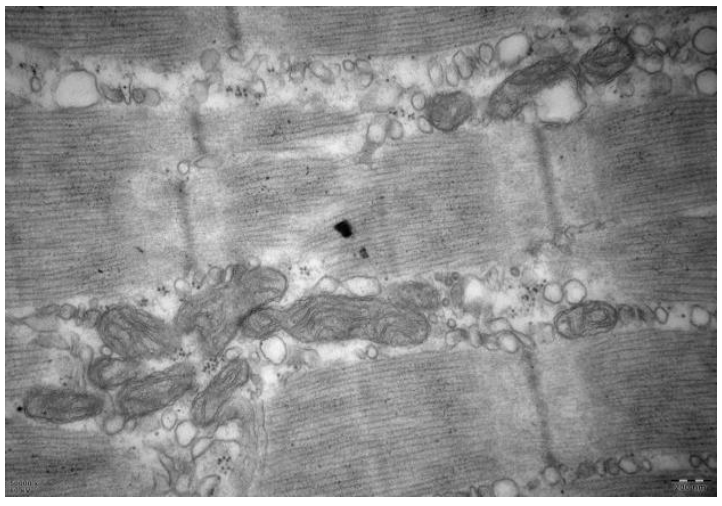

$\mathbf{E}$

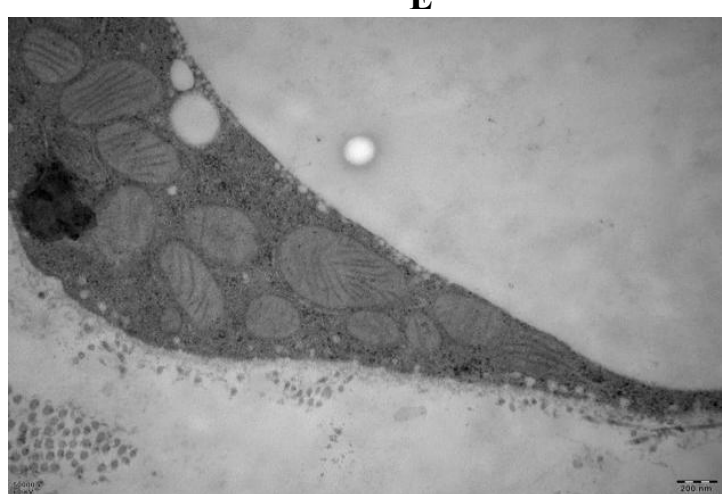

B

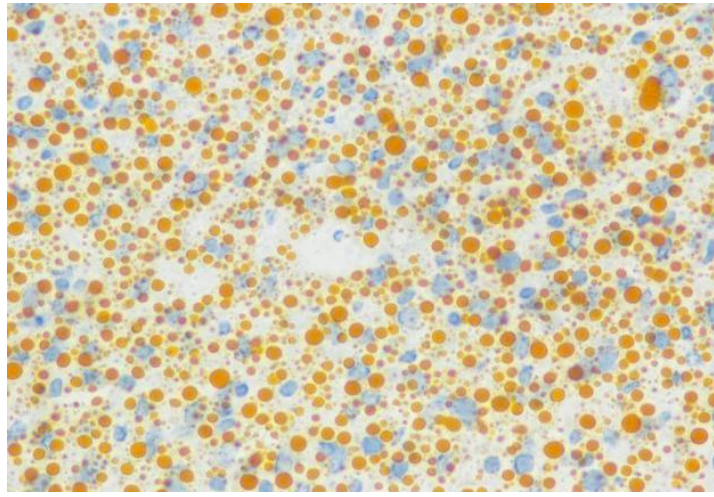

D

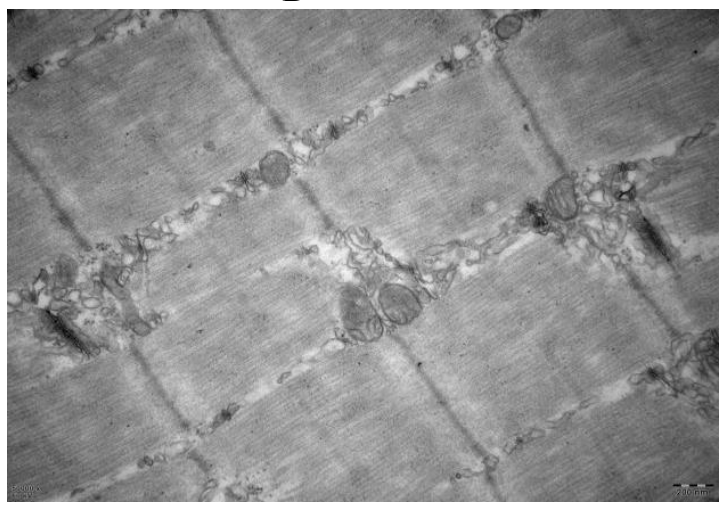

$\mathbf{F}$

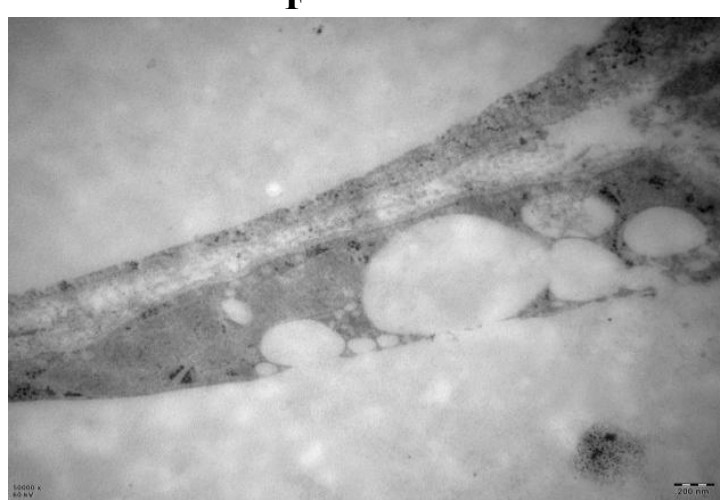

Fig. 8 CS-induced fatty liver-like lipogenesis and NALFD-related gene upregulation in AL and CS mice. A. Oil red O stained hepatic tissues of an AL mouse (200x). B. Oil red O stained hepatic tissues of a CS mouse (200x). C. Mitochondrial morphology in muscular tissues of an AL mouse. D. Mitochondrial morphology in muscular tissues of a CS mouse (50000x). E. Mitochondrial morphology in adipose tissues of an AL mouse (50000x). F. Mitochondrial morphology in adipose tissues of a CS mouse $(50000 \times)$. 


\section{Discussion}

Considering the emerging findings that $\mathrm{CS}$ induces sulfatase secretion from $B$. thetaiotaomicron, one of the bacterial species belonging to SSB, and thus nourishes $D$. piger, one of the bacterial species belonging to SRB [13], we hypothesized that CS-mediated gut opportunistic infection by SSB and SRB might be a potential trigger that reduces colon lining integrity, allows LPS leakage, induces chronic low-grade inflammation and initiates systemic pathogenesis towards multiple inflammatory diseases, including Alzheimer's disease [24]. In the present study, we noticed for the first time that CS induces the early-phase and multi-systemic pathogenesis towards dementia, arthritis, tumor and fatty liver by modulating the corresponding hallmarks, i.e., $\mathrm{A} \beta$ upregulation for dementia, RF upregulation for arthritis, $\mathrm{CD} 1$ upregulation/p21 downregulation for tumor, and NAFLD-related gene overexpression for fatty liver. In particular, a synchronous decline of TH, Ach and ChAT levels was monitored in CS-fed mice, suggesting a hint initiating progressive cognitive deficits seen in LPS-challenged mice [25]. Moreover, arthritis-like erythematous and edematous paws, tumor-like neoplasia and fatty liver-like lipogenesis were also typically observed in CS-fed mice.

We also detected an overexpression of the transcription factor BCL11A that is overexpressed in the triplet negative breast cancer (TNBC) in the mammary tissues of CS-BC and LPS female mice. Recently, it was highlighted that exogenous BCL11A overexpression promotes tumor formation, whereas its knockdown suppresses tumorigenic proliferation, suggesting that BCL11 A has a critically promoting role in TNBC [26]. As a newly identified prognostic indicator of TNBC that correlates with poor prognosis in TNBC patients [27], RUNX1 was also found upregulation in the mammary tissues of CS-BC and LPS female mice. Similarly, TP53BP1, an activator of the tumor suppressor p53 that is associated with TNBC [28], was also observed to have the raised mRNA levels in the mammary tissues of CS-BC and LPS female mice.

Our previous work indicated that live Escherichia coli feeding induces articular synovitis accompanying with the upregulation of iNOS and burst of NO [29]. Recently, A. muciniphila as a common member of SSB has been shown to allow mucus thinning, LPS leaking and epithelial proliferation [14]. As evidence supporting LPS-mediated neurodegenerative disease, a species of gut bacteria was found to be correlated to the clinical phenotype of Parkinson's disease [11]. It was also revealed that LPS and K99 derived from Gram negative bacteria exist in the amyloid plaques of dementia patients' brain [30]. Furthermore, it was verified a pathogenic mechanism underlying a specific gut microbiota induces neuroinflammation and causes cognitive degeneration in patients with Parkinson's disease [31].

In this experimental observation, we unambiguously noted a coherent changes of sulfatase and mucin expression with leukocyte activation. When sulfatase is overexpressed, SLPI is upregulated, and MUC1/4 is accordingly overproduced. In other words, mucus repairs are enhanced after colon lesions. By nourishing SSB, CS was found to elevate serum LPS levels and upregulate TNF- $\alpha$ in multiple tissues, implying gut leakage and LPS entry into the blood circulation. As similar as bacteremia leading to sepsis and septic shock, LPS entering into the bloodstream can trigger a potent immune response in a titer-dependent manner. While high-titer LPS resembling acute bacterial infection induces neutralizing antibodies for elimination of LPS, low-titer LPS resembling chronic bacterial infection slightly elevates the levels of pro-inflammatory cytokines for two to three folds, leading to low-grade inflammation and initiating diabetes mellitus and fatty 
liver diseases [23].

Interestingly, we observed that LPS and TNF- $\alpha$ levels in adipose tissues are different from those in other tissues. Briefly, LPS and TNF- $\alpha$ levels in adipose tissues are declined at first, but elevated later. In contrast, LPS and TNF- $\alpha$ levels in other tissues are first elevated, but then declined. This intriguing phenomenon seemed to be explained by a finding that SRB1 binds to LPS and incorporates it into chymicrons, which are later enhanced transcytosis over the endothelial barrier and endocytosis of adipocytes [32]. From this clue, we deciphered that adipose tissues should uptake high-level LPS and enhance antibody induction and LPS eradication. Due to the interaction of SRB1 with LPS, the concentration of LPS must eventually be higher than the titer of anti-LPS, which should allow LPS accumulation in adipose tissues to elevate TNF- $\alpha$ levels. Without a specific role of LPS-SRBI in other tissues, the concentration of LPS could not be higher than the titer of anti-LPS, so LPS and TNF- $\alpha$ should be converted from higher levels to lower ones.

Logically, if serological tests would be performed, the inflammatory indicators should be lower (in an anti-inflammatory phase). In contrast, if tests would be conducted using a tissue sample, the inflammatory indicators should be higher (in a pro-inflammatory stage). Accordingly, we found in the present study that LPS upregulates the NALFD-related genes in a large scale. However, our recent work indicated that most of the NALFD-related genes are downregulated in CS mice as compared with AL mice [33]. The latter result addressed that CS might not raise the hepatic LPS level to upregulate the NALFD-related genes, otherwise it should have reduced the hepatic LPS level to downregulate the NALFD-related genes. Indeed, this explanation can be supported by the low hepatic LPS level in CS mice tested in this study, suggesting that the residual LPS might have been eventually eradicated by the neutralizing anti-LPS antibody. Nevertheless, some other NALFD-related genes were still observed to be upregulated in a different manner and an unknown mechanism.

It has been documented that CS shows differential results in dealing with OA, i.e., some reports demonstrating effective $[15,16]$, but others addressing ineffective $[18,19]$. For this discrepancy, it might be simply deciphered by an individual gut microbiota specificity. CS should exert anti-inflammatory effects and ameliorate OA when SSB are absent or rare in the gut, otherwise it should exert pro-inflammatory effects and aggravate OA. In the present study, we noticed a synovitis-like phenotype in CS.RA with the overgrown SSB (B.cereus), but not in CS.HL without the overgrown SSB. However, it remains inclusive why CS.NM with the overgrown SSB (A.muciniphila) does not show synovitis. In our recent finding, A.muciniphila was observed to induce mucin expression and reinforce mucus integrity, thereby compromising LPS-mediated pro-inflammatory stimuli [33]. Accumulating evidence supports that $A$. muciniphila has therapeutic values in metabolic diseases, including an inverse correlation of $A$. muciniphila with obesity and diabetes in mice and humans [34, 35].

On the other hand, a pro/anti-inflammatory role of CS on OA might be also explained by a time-dependent condition, in which CS is effective against OA once LPS is eradicated by anti-LPS in a later stage, otherwise OA should be deleterious because LPS levels are higher in an early period. In this study, we found that most tissues in CS mice exhibit the pro-inflammatory responses at first, but then exert an anti-inflammatory effect later. Accordingly, LPS and TNF- $\alpha$ levels are higher in an early phase of CS feeding, but both levels are declined in the late period. These results indicated that CS may eventually show an anti-inflammatory effect by raising LPS levels to induce anti-LPS generation in almost all tissues except for adipose tissues. In our 
previous work, we surprisingly found that a relative higher dose of LPS $(1.2 \mathrm{mg} / \mathrm{kg})$ leads to a peritoneally anti-inflammatory state, whereas a relative lower dose of LPS $(0.25 \mathrm{mg} / \mathrm{kg})$ causes a viscerally pro-inflammatory state, implying anti-LPS neutralizing LPS in peritoneal organs but not in visceral organs [23].

LPS can bind to TLR4 on cell surface to activate NF- $\mathrm{BB}$ for upregulation of pro-inflammatory cytokines including TNF- $\alpha$ and IL-1 $\beta$ [36]. Actually, we detected the synchronous upregulation of LPS, TNF- $\alpha$ and TNFR1. After depletion of LPS, iNOS-derived high-level NO should be blocked, and eNOS-derived NO would be rehearsed, thereby activating adenosine monophosphateactivated protein kinase (AMPK) and initiating mitochondrial biogenesis [37]. Alternatively, AMPK can in turn activate eNOS by the signaling cascade AMPK $\rightarrow$ Rac1 $\rightarrow$ Akt $\rightarrow$ eNOS [38]. Furthermore, it has been raveled that AMPK can catalyze the phosphorylation of JAK2 and inhibit its pro-inflammatory activity via JAK2-STAT3 signaling [39]. The extracellular infection by pathogenic microorganisms can activate NADP oxidase to trigger the burst of reactive oxygen species (ROS), which upregulates the pro-inflammatory cytokine expression and augment the pro-inflammatory response [40]. It was accepted that TNF- $\alpha$, IL-1 $\beta$ and other pro-inflammatory cytokines can upregulate iNOS for NO production, and that $\mathrm{NO}$ as a hypoxic inducer can activate HIF- $1 \alpha[41,42]$.

In our previous work [29], we showed that the NO donor sodium nitroprusside can activate HIF- $1 \alpha$ and upregulate hypoxia-responsive genes such as VEGF. On the other hand, EPO, a glycoprotein hormone indispensable for erythropoiesis, was validated to reduce blood glucose and body mass in mice [43]. Additionally, EPO was thought to have other biological activities that extend to nonerythroid tissues, such as inhibition of adipose inflammation, normalization of insulin sensitivity, and reduction of glucose intolerance [44]. In this investigation, we observed the elevation of iNOS, HIF-1 $\alpha$, EPO and VEGF levels in adipose tissues of CS mice, suggesting a hypoxic milieu leading to mitochondrial dysfunction and deficiency among other abnormal outcomes. Accordingly, we detected the downregulation of MFN2 and CSCS, two common mitochondrial biomarkers [45], in the most tested tissues of CS mice, implying compromised mitochondrial biogenesis and mitigated lipid degradation. Indeed, we noticed that the numbers and sizes of mitochondria are dramatically decreased in muscular and adipose tissues of CS mice. We also found that a large number of condensed oil droplets are accumulated in hepatic tissues by CS feeding, perhaps due to without sufficient mitochondria for fatty acid degradation.

\section{Conclusions}

The animal-based dietary sulfate CS would initiate the onset of multi-systemic inflammatory pathogenesis by nourishing the mucin-degrading microbiota and compromising the mucus-protecting function. CS might be beneficial or harmful to OA depending on the absence or presence of SSB and SRB. Upon interaction with SSB and SRB, CS induces multi-systemic pathogenesis towards arthritis, dementia, tumor and fatty liver although they maintain in a mild state and during an early stage.

\section{List of abbreviations}

$\mathrm{A} \beta$ : amyloid $\beta$ peptide; ACh: acetylcholine; AL: ad libitum chow; AMPK: adenine monophosphate-activated protein kinase; CCL2: chemokine (C-C motif) ligand 2; CD1: cyclin D1; ChAT: choline acetyltransferase; CS: chondroitin sulfate; CSCS: cytochrome $c$, somatic; ELISA: 
enzyme-linked immunosorbent assay; EPO: erythropoietin; GAPDH: glyceraldehyde-3-phosphate dehydrogenase; HE: haematoxylin-eosin; HIF-1 $\alpha$ : hypoxia induced factor $1 \alpha$; LPS:

lipopolysaccharide; IL-1: interleukin 1; iNOS: inducible nitric oxide synthase; MFN2: mitofusin 2; MUC: mucin; NALFD: non-alcoholic fatty liver disease; NO: nitric oxide; PCR: polymerase chain reaction; PS-1: presenilin 1; qPCR: quantitative real-time PCR; RF: rheumatoid factor; TH: tyrosine hydroxylase; TLR4: toll-like receptor 4; TNBC: triplet negative breast cancer; TNF- $\alpha$ : tumor necrosis factor $\alpha$; TNFR1: TNF- $\alpha$ receptor 1; SLPI: secretory leukocyte protease inhibitor; SRB: sulfate-reducing bacteria; SSB: sulfatase-secreting bacteria; VEGF: vascular epithelial growth factor; WB: Western blotting.

\section{Declarations}

\section{Ethics approval and consent to participate}

All subjects signed written consent to participate in this study. This study was approved by The Animal Care Welfare Committee of Guangzhou University of Chinese Medicine (No. SPF-2015009).

\section{Consent for publication}

Not applicable.

\section{Availability of data and materials}

The datasets supporting the conclusions of this article are included within the article (Additional file 1 includes primer sequence data, Additional file 2 includes gut microbiota metagenomic data, and Additional file 3 includes fatty liver-related gene microarray data).

\section{Competing interests}

The authors declare that they have no competing interests.

\section{Funding}

This work was supported by the National Natural Science Foundation of China (No. 81273620 to Qing-Ping Zeng, No. 81673861 to Chang-Qing Li, and No. 81273817 and No. 81473740 to Qi Wang), and Guangdong Science and Technology Plan Project (No. 20150404042 to Qin Xu).

\section{Acknowledgments}

We thank our colleagues in the Tropical Medicine Institute and Clinical Pharmacology Institute, Guangzhou University of Chinese Medicine, China. We also thank Kangchen Biotechnology Co, Shanghai, China for performance of RT-PCR array experiments, and Novogene, Beijing, China for conduction of gut microbiota metagenomic analysis.

\section{Authors contributions}

QPZ, QW and QX designed the study. TL, YPC, and LLT carried out the experiments. XAH performed bioinformatics analysis. CQL, QW and QX participated in the interpretation of results. QPZ wrote the manuscript with input from other authors. All authors read and approved the final manuscript.

\section{References}

[1] Zhernakova A, Kurilshikov A, Bonder MJ, Tigchelaar EF, Schirmer M, Vatanen T, Mujagic Z, Vila AV, Falony G, Vieira-Silva S, Wang J, Imhann F, Brandsma E, Jankipersadsing SA, Joossens M, Cenit MC, Deelen P, Swertz MA, LifeLines cohort study, Weersma RK, Feskens EJ, Netea 
MG, Gevers D, Jonkers D, Franke L, Aulchenko YS, Huttenhower C, Raes J, Hofker MH, Xavier $\mathrm{RJ}$, Wijmenga C, Fu J. Population-based metagenomics analysis reveals markers for gut microbiome composition and diversity. Science. 2016;352:565-9.

[2] Wu GD, Chen J, Hoffmann C, Bittinger K, Chen YY, Keilbaugh SA, Bewtra M, Knights D, Walters WA, Knight R, Sinha R, Gilroy E, Gupta K, Baldassano R, Nessel L, Li H, Bushman FD, Lewis JD. Linking long-term dietary patterns with gut microbial enterotypes. Science. 2011;334:105-8.

[3] Kovatcheva-Datchary P, Nilsson A, Akrami R, Lee YS, De Vadder F, Arora T, Hallen A, Martens E, Björck I, Bäckhed F. Dietary fiber-induced improvement in glucose metabolism is associated with increased abundance of Prevotella. Cell Metab. 2015;22:971-82.

[4] David LA, Maurice CF, Carmody RN, Gootenberg DB, Button JB, Wolfe BE, Ling AV, Devlin AS, Varma Y, Fischbach MA, Bidinger SB, Dutton RJ, Turnbaugh PJ. Diet rapidly and reproducibly alters the human gut microbiome. Nature. 2014;505:559-63.

[5] De Filippo C, Cavalieri D, Di Paola M, Ramazzotti M, Poullet JB, Massart S, Collini S, Pieraccini $G$, Lionetti $P$. Impact of diet in shaping gut microbiota revealed by a comparative study in children from Europe and rural Africa. Proc Natl Acad Sci USA. 2010;107:14691-6.

[6] Wang Z, Klipfell E, Bennett BJ, Koeth R, Levison BS, Dugar B, Feldstein AE, Britt EB, Fu X, Chung YM, Wu Y, Schauer P, Smith JD, Allayee H, Tang WH, DiDonato JA, Lusis AJ, Hazen SL. Gut flora metabolism of phosphatidylcholine promotes cardiovascular disease. Nature. 2011;472:57-63.

[7] Cotillard A, Kennedy SP, Kong LC, Prifti E, Pons N, Le Chatelier E, Almeida M, Quinquis B, Levenez F, Galleron N, ANR MicroObes consortium, Doré J, Zucker JD, Clément K, Ehrlich SD. Dietary intervention impact on gut microbial gene richness. Nature. 2013;500:585-8.

[8] Le Chatelier E, Nielsen T, Qin J, Prifti E, Hildbrand F, Falony G, Almeida M, Batto JM, Kennedy S, Leonard P, Li J, Burgdorf K, Grarup N, Jørgensen T, Brandslund I, Nielsen HB, Juncker AS, Bertalan M, Levenez F, Pons N, Rasmussen S, Sunagawa S, Tap J, Tims S, Zoetendal EG, Brunak S, Clément K, Doré J, Kleerebezem M, Kristiansen K, Renault P, Sicheritz-Ponten T, de Vos WM, Zucker JD, Raes J, Hansen T; MetaHIT consortium., Bork P, Wang J, Ehrlich SD, Pedersen O. Richness of human gut microbiome correlates with metabolic markers. Nature. 2013;541-6.

[9] Qin J, Li Y, Cai Z, Li S, Zhu J, Zhang F, Liang S, Zhang W, Guan Y, Shen D, Peng Y, Zhang D, Jie Z, Wu W, Qin Y, Xue W, Li J, Han L, Lu D, Wu P, Dai Y, Sun X, Li Z, Tang A, Zhong S, Li X, Chen W, Xu R, Wang M, Feng Q, Gong M, Yu J, Zhang Y, Zhang M, Hansen T, Sanchez G, Raes J, Falony G, Okuda S, Almeida M, Le Chatelier E, Renault P, Pons N, Batto JM, Zhang Z, Chen H, Yang R, Zheng W, Li S, Yang H, Wang J, Ehrlich SD, Nielsen R, Pedersen O, Kristiansen K, Wang J. A metagenome-wide association study of gut microbiota in type 2 diabetes. Nature. 2012;490:55-60.

[10] Karlsson FH, Tremaroli V, Nookaew I, Bergstrom G, Behre CJ, Fagerberg B, Nielsen J, Backhed F. Gut meta genome in European women with normal, impaired and diabetic glucose control. Nature. 2013;498:99-103.

[11] Scheperjans F, Aho V, Pereira PA, Koskinen K, Paulin L, Pekkonen E, Haapaniemi E, Kaakkola S, Eerola-Rautio J, Pohja M, Kinnunen E, Murros K, Auvinen P. Gut microbiota are related to Parkinson's disease and clinical phenotype. Mov Disord. 2015;30:350-8.

[12] Koeth RA, Wang Z, Levison BS, Buffa JA, Org E, Sheehy BT, Britt EB, Fu X, Wu Y, Li L, Smith JD, DiDonato JA, Chen J, Li H, Wu GD, Lewis JD, Warrier M,Brown JM, Krauss RM, Tang WH, Bushman FD, Lusis AJ, Hazen SL. Intestinal microbiota metabolism of L-carnitine, a nutrient in red meat, promotes atherosclerosis. May Med. 2013;19:576-85. 
[13] Rey FE, Gonzalez MD, Cheng J, Wu M, Ahern PP, Gordon JI. Metabolic niche of a prominent sulfate-reducing human gut bacterium. Proc Natl Acad Sci USA. 2013;110:13582-7.

[14] ljssennager N, Belzer C, Hooiveld GJ, Dekker J, van Mil SW, Müller M, Kleerebezem M, van der Meer R. Gut microbiota facilitates dietary heme-induced epithelial hyper-proliferation by opening the mucus barrier in colon. Proc Natl Acad Sci USA. 2015;112:10038-43.

[15] Segarra S, Martinez-Subiela S, Cerda-Cuellar M, Martinez-Puig D, Munoz-Prieto A, Rodriguez-Franco F, Rodriguez-Bertos A, Allenspach K, Velasco A, Ceron J. Oral chondroitin sulfate and probiotics for the treatment of cannie inflammatory bowel disease: a randomized, controlled clinical trial. BMC Vet Res. 2016;12:49.

[16] Clegg DO, Reda DJ, Harris CL, Klein MA, O'Dell JR, Hooper MM, Bradley JD, Bingham CO 3rd, Weisman MH, Jackson CG, Lane NE, Cush JJ, Moreland LW, Schumacher HR Jr, Oddis CV, Wolfe F, Molitor JA, Yocum DE, Schnitzer TJ, Furst DE, Sawitzke AD, Shi H, Brandt KD, Moskowitz RW, Williams HJ. Glucosamine, chondroitin sulfate, and the two in combination for painful knee osteoarthritis. New Eng J Med. 2006;354:795-808.

[17] Jevseva DS, Brown GA, Jones DL, Matzkin EG, Manner PA, Mooar P, Schousboe JT, Stovitz S, Sanders JO, Bozic KJ, Goldberg MJ, Martin WR 3rd, Cummins DS, Donnelly P, Woznica A, Gross L;American Academy of Orthopaedic Surgeons., The American Academy of orthopaediac surgeons evidence-based guideline on: treatment of osteoarthritis of the knee, 2nd edition. J Bone Joint Surgery Am. 2013;95:1885-6.

[18] Roman-Blas JA, Mediero A, Tardio L, Portal-Nunez S, Gratal P, Herrero-Beaumont G, Largo R. The combined therapy with chondroitin sulfate plus glucosamine sulfate or chondroitin sulfate plus glucosamine hydrochloride does not improve joint damage in an experimental model of knee osteoarthritis in rabbits. Eur J Pharmacol. 2017;794:8-14.

[19] Roman-Blas JA, Castaneda S, Sanchez-Pernaute O, Largo R, Herrero-Beaumont G, CS/GS Combined Therapy Study Group. Combined treatment with chondroitin sulfate and glucosamine sulfate shows no superiority over placebo for reduction of joint pain and functional impairment in patients with knee osteoarthritis: a six-month multicenter, randomized, double-bland, placebo-controlled clinical trial. Arthritis Rheumatol. 2017;69:77-85.

[20] Shang Q, Yin Y, Zhu L, Li G, Yu G, Wang X. Degradation of chondroitin sulfate by the gut microbiota of Chinese individuals. Int J Biol Micromol. 2016;86:112-8.

[21] Shang Q, Shi J, Song G, Zhang M, Cai C, Hao J, Li G, Yu G. Structural modulation of gut microbiota by chondroitin sulfate and its oligosaccharide. Int J Biol Micromol. 2016;89:489-98.

[22] He Q, Yu W, Wu J, Chen C, Lou Z, Zhang Q, Zhao J, Wang J, Xiao B. Intranasal LPS-mediated Parkinson's model challenges the pathogenesis of nasal cavity and environmental toxins. PLoS One. 2013;8:e78418.

[23] Gao Q, He J, Liao T, Zeng QP. 2,4-dinitrophenol downregulates genes for diabetes and fatty liver in obese mice. J Biosci Med. 2015;3:44-51.

[24] Li CQ, Zheng Q, Wang Q, Zeng QP. Biotic/abiotic stress-driven Alzheimer's disease. Front Cell Neurosci. 2016;10:269.

[25] He J, Liao T, Zhong GX, Zhang JD, Chen YP, Wang Q, Zeng QP. Alzheimer's disease-like early-phase brain pathogenesis: self-curing amelioration of neurodegeneration from pro-inflammatory 'wounding' to anti-inflammatory 'healing'. Cur Alzheimer Res. 2016; .

[26] Khaled WT, Choon Lee S, Stingl J, Chen X, Raza Ali H, Rueda OM, Hadi F, Wang J, Yu Y, Chin SF, Stratton M7, Futreal A, Jenkins NA, Aparicio S, Copeland NG, Watson CJ, Caldas C, Liu P. 
$\mathrm{BCL} 11 \mathrm{~A}$ is a triple-negative breast cancer gene with critical functions in stem and progenitor cells. Nat Comms. 2015;6:5987.

[27] Ferrari N, Mohammed ZM, Nixon C, Mason SM, Mallon E, McMillan DC, Morris JS, Cameron ER, Edwards J, Blyth K. Expression of RUNX1 correlates with poor patient prognosis in triplet negative breast cancer. PLoS One. 2019:e100759.

[28] Bouwman P, Aly A, Escandell JM, Pieterse M, Bartkova J, van der Gulden H, Hiddingh S, Thanasoula M, Kulkarni A, Yang Q, Haffty BG, Tommiska J, Blomqvist C, Drapkin R, Adams DJ, Nevanlinna H, Bartek J, Tarsounas M, Ganesan S, Jonkers J. 53BP1 loss rescues BRCA1 deficiency and is associated with triple-negative and BRCA-mutated breast cancers. Nat Struct Mol Biol. 2010;17:688-95.

[29] Bao F, Wu P, Xiao N, Qiu F, Zeng QP. Nitric oxide-driven hypoxia initiates synovial angiogenesis, hyperplasia and inflammatory lesions. PLoS One. 2012;7:e34494.

[30] Zhan X, Stamova B, Jin LW, DeCarli C, Phinney B, Sharp FR.Gram-negative bacterial molecules associate with Alzheimer's disease pathology. Neurology. 2016;87:2324-32.

[31] Sampson T, Debelius JW, Thron T, Janssen S, Shastri GG, Ilhan ZE, Challis C, Schretter CE, Rocha S, Gradinaru V, Chesselet MF, Keshavarzian A, Shannon KM, Krajmalnik-Brown R, Wittung-Stafshede P, Knight R, Mazmanian SK. Gut microbiota regulates motor deficits and neuroinflammation in a morsel of Parkinson's disease. Cell. 2016;167:1469-80.

[32] Hersoug LG, Moller P, Loft S. Gut microbiota-derived lipopolysaccharide uptake and trafficking to adipose tissue: implication for inflammation and obesity. Obes Rev. 2016;17:297-312.

[33] Liao T, Chen YP, Huang SQ, Tan LL, Li CQ, Huang XA, Xu Q, Wang Q, Zeng QP. Chondroitin sulfate elicits systemic pathogenesis in mice by interfering with gut microbiota homeostasis. BioRxiv 2017; doi: https://doi.org/10.1101/142588.

[34] Shin NR, Lee JC, Lee HY, Kim MS, Whon TW, Lee MS, Bae JW. An increase in the Akkermansia spp. population induced by metformin treatment improves glucose homeostasis in diet-induced obese mice. Gut. 2014; 63:727-35.

[35] Dao MC, Everard A, Aron-Wisnewsky J, Sokolovska N, Prifti E, Verger EO, Kayser BD, Levenez F, Chilloux J, Hoyles L. MICRO-Obes Consortium, Dumas ME, Rizkalla SW, Doré J, Cani PD, Clément K. Akkermansia muciniphila and improved metabolic health during a dietary intervention in obesity: relationship with gut microbiome richness and ecology. Gut. 2016; 65: 426-36.

[36] Baker RG, Hayden MS, Ghosh S. NF-kB, inflammation, and metabolic disease. Cell Metab. 2011;13:11-2.

[37] Wang DT, He J, Wu M, Li SM, Gao Q, Zeng QP . Artemisinin mimics calorie restriction to trigger mitochondrial biogenesis and compromise telomere shortening in mice. Peer J. 2015;3:e822.

[38] Levene YC, Li GK, Michel T. Agonist-modulated regulation of AMP-activated protein kinase in endothelial cells: evidence for an AMPK $\rightarrow$ Rac1 $\rightarrow$ Akt $\rightarrow$ eNOS pathway. J Biol Chem. 2007. 282:20351-64.

[39] Ruthford C, Spiers C, Williams JKL, Ewart MA, Mancini SJ, Hawley SA, Delles C, Viollet B, Costa-Pereira AP, Baillie GS, Salt IP, Palmer TM. Phosphorylation of Janus kinase 1 (JAK1) by AMP-activated protein kinase (AMPK) links energy sensing to anti-inflammatory signaling. Sci Signal. 2016;9:ra109.

[40] Cho SO, Lim JW, Kim HY. Red ginseng extracts inhibit the expression of MCP-1 and iNOS in Helicobactor pylori-infected gastric epithelial cells by suppression of NADH oxidase and Jak2/Stat3. J Ethnopharmacol. 2013;150:761-4. 
[41] Ratarajan R, Fisher BJ, Follor III AA. Regulation of hypoxia inducible factor 1 by nitric oxide in contrast to hypoxia in microvascular endothelium. FEBS Lett. 2003;549:99-104.

[42] Kasuno K, Takabuchi S, Fukuda K, Kizaka-Kondoh S, Yadoi J, Adachi T, Semenza GL, Hirota K. Nitric oxide induces hypoxia inducible factor 1 activation that is dependent on MAPK and phosphatidylinositol 3-kinase signaling. J Biol Chem. 2004;279:2550-8.

[43] Katz O, Stuible M, Golishevski N, Lifshitz L, Tremblay ML, Gasmann M, Mittleman M, Neumann D. Erythropoietin treatment leads to reduced blood glucose levels and body mass: insights from murine models. J Endochrinol. 2010; 205:87-95.

[44] Alnaeeli M, Raaka BM, Gavrinova O, Teng R, Chanturiya T, Noguch CT. Erythropoietin signaling: a novel regulator of white adipose tissue inflammation during diet-induced obesity. Diabetes. 2014;63:2415-31.

[45] Cerqueira FM, Laurindo FRM, Kowatowski AJ. Mild mitochondial uncoupling and calorie restriction increases fasting eNOS, Akt and mitochondrial biogenesis. PLoS One. 2011;6:e18433. 